\title{
p110 $\delta$ PI3-Kinase Inhibition Perturbs APP and TNF $\alpha$ Trafficking, Reduces Plaque Burden, Dampens Neuroinflammation, and Prevents Cognitive Decline in an Alzheimer's Disease Mouse Model
}

\author{
๑Ramón Martínez-Mármol, ${ }^{1}$ Nika Mohannak, ${ }^{1 *}$ ¿Lei Qian, ${ }^{1,2 *}$ Tong Wang, ${ }^{1}$ ○Rachel S. Gormal, ${ }^{1}$ \\ (D)Marc J. Ruitenberg, ${ }^{2}$ B Bart Vanhaesebroeck, ${ }^{3}$ (DElizabeth J. Coulson, ${ }^{1,2}$ and (Drédéric A. Meunier ${ }^{1}$ \\ ${ }^{1}$ Clem Jones Centre for Ageing Dementia Research, Queensland Brain Institute, The University of Queensland, Brisbane 4072, Australia, ${ }^{2}$ School of \\ Biomedical Sciences, Faculty of Medicine, The University of Queensland, Brisbane 4072, Australia, and ${ }^{3}$ Cell Signalling, University College London Cancer \\ Institute, London WC1E 6DD, United Kingdom
}

\begin{abstract}
Alzheimer's disease $(\mathrm{AD})$ is associated with the cleavage of the amyloid precursor protein (APP) to produce the toxic amyloid- $\beta$ (A $\beta$ ) peptide. Accumulation of $\mathrm{A} \beta$, together with the concomitant inflammatory response, ultimately leads to neuronal death and cognitive decline. Despite AD progression being underpinned by both neuronal and immunological components, therapeutic strategies based on dual targeting of these systems remains unexplored. Here, we report that inactivation of the p110 $\delta$ isoform of phosphoinositide 3-kinase $(\mathrm{PI} 3 \mathrm{~K})$ reduces anterograde axonal trafficking of APP in hippocampal neurons and dampens secretion of the inflammatory cytokine tumor necrosis factor-alpha by microglial cells in the familial AD APP ${ }_{\text {swe }} / \mathrm{PS} 1_{\Delta \mathrm{E} 9}(\mathrm{APP} / \mathrm{PS} 1)$ mouse model. Moreover, APP/PS1 mice with kinase-inactive $\mathrm{PI} 3 \mathrm{~K} \delta\left(\delta^{\mathrm{D} 910 \mathrm{~A}}\right)$ had reduced $\mathrm{A} \beta$ peptides levels and plaques in the brain and an abrogated inflammatory response compared with APP/PS1 littermates. Mechanistic investigations reveal that PI3K $\delta$ inhibition decreases the axonal transport of APP by eliciting the formation of highly elongated tubular-shaped APP-containing carriers, reducing the levels of secreted A $\beta$ peptide. Importantly, APP/PS1 $/ \delta^{\mathrm{D} 910 \mathrm{~A}}$ mice exhibited no spatial learning or memory deficits. Our data highlight inhibition of PI3K $\delta$ as a new approach to protect against $\mathrm{AD}$ pathology due to its dual action of dampening microglial-dependent neuroinflammation and reducing plaque burden by inhibition of neuronal APP trafficking and processing.
\end{abstract}

Key words: Alzheimer's disease; amyloid precursor protein; axon trafficking; neuroinflammation; p110delta; TNF-alpha

Significance Statement

During Alzheimer's disease (AD), the accumulation of the toxic amyloid- $\beta(\mathrm{A} \beta)$ peptide in plaques is associated with a chronic excessive inflammatory response. Uncovering new drug targets that simultaneously reduce both $\mathrm{A} \beta$ plaque load and neuroinflammation holds therapeutic promise. Using a combination of genetic and pharmacological approaches, we found that the $\mathrm{p} 110 \delta$ isoform of phosphoinositide 3-kinase (PI3K) is involved in anterograde trafficking of the amyloid precursor protein in neurons and in the secretion of tumor necrosis factor-alpha from microglial cells. Genetic inactivation of PI $3 \mathrm{~K} \delta$ reduces $\mathrm{A} \beta$ plaque deposition and abrogates the inflammatory response, resulting in a complete rescue of the life span and spatial memory performance. We conclude that inhibiting $\mathrm{PI} 3 \mathrm{~K} \delta$ represents a novel therapeutic approach to ameliorate $\mathrm{AD}$ pathology by dampening plaque accumulation and microglial-dependent neuroinflammation.

\section{Introduction}

Alzheimer's disease $(\mathrm{AD})$ is characterized by the accumulation of toxic amyloid- $\beta$ (A $\beta)$ peptide, which leads to synaptic dysfunc- tion, axonal degeneration, and, ultimately, neuronal death (Selkoe, 2002). Two complementary systems play essential roles in

the paper; R.M.-M., T.W., R.S.G., M.J.R., B.V., E.J.C., and F.A.M. edited the paper; R.M.-M. and F.A.M. wrote the paper.

This work was supported by the National Health and Medical Research Council (NHMRC) (Project Grants 1049236 to E.J.C., 1005964 to F.A.M., and 1060538 to M.J.R.). Work in the laboratory of B.V. is supported by the Biotechnology 
the pathogenesis and progression of $\mathrm{AD}$ : neuronal dysfunction and inflammation.

The neuronal aspect involves the aggregation of secreted $A \beta$ into fibrils and its deposition in amyloid plaques, one of the main pathological hallmarks of AD (Dickson, 1997). Although the primary event that results in the abnormal accumulation of $A \beta$ is thought to be a dysregulated proteolytic processing of the amyloid precursor protein (APP), the specific cellular location of APP cleavage and $A \beta$ release remains unclear. Endogenous APP is present, however, in presynaptic vesicles that undergo stimulationdependent exo-endocytic recycling (Groemer et al., 2011), and axonal tracks have been shown to be crucial compartments in the production of $\mathrm{A} \beta$ (Stokin et al., 2005).

The immune system also plays a significant role in $\mathrm{AD}$ progression. Indeed, the development of amyloid plaques is associated with glial activation (i.e., hemopoietic-derived astrocytes and microglia) and the secretion of proinflammatory cytokines by these cells (Wyss-Coray et al., 2001). Although it is thought that the inflammatory response has a beneficial impact in dampening the early stages of disease progression, chronic neuroinflammation and the associated production of proinflammatory cytokines ultimately lead to neuronal death (Mandrekar-Colucci and Landreth, 2010). One of the earliest proinflammatory cytokines released from microglia is tumor necrosis factor-alpha (TNF $\alpha$ ). Excessive secretion of TNF $\alpha$ as a result of neuroinflammation causes neuronal apoptosis, which is also observed during $\mathrm{AD}$ (Collins et al., 2000). Furthermore, elevated TNF $\alpha$ levels promote $\mathrm{A} \beta$ production (Liao et al., 2004), thereby driving a vicious cycle of chronic neuroinflammation and disease progression. Blocking TNF $\alpha$ signaling therefore has the potential to decrease $\mathrm{A} \beta$-associated neuroinflammation to attenuate $\mathrm{AD}$ progression. However, undesired secondary effects have been observed when the downstream signaling of the TNF $\alpha$ pathway is completely inhibited (Montgomery et al., 2013). Blocking the release of excessive pathogenic TNF $\alpha$ while maintaining homeostatic basal pools of this cytokine is therefore considered a more cautious and pragmatic therapeutic approach to control neuroinflammation in conditions such as AD or stroke (Low et al., 2014).

Phosphoinositide 3-kinases (PI3Ks) are modulators of cellular membrane lipids involved in signaling and trafficking events. In the brain, PI3K $\delta$ is expressed in neurons and microglia (Eickholt et al., 2007; Low et al., 2014; Hood et al., 2019). Despite its established role in controlling functions in autoimmunity and inflammation (Okkenhaug and Vanhaesebroeck, 2003; Ali et al., 2014), the role of PI3K $\delta$ in neurons remains largely unknown,

and, Biological Sciences Research Council (BB/1007806/1), Cancer Research UK (C23338/A25722) and the National Institute for Health Research (NIHR) University College London Hospitals Biomedical Research Centre. F.A.M. is supported by an NHMRC Senior Research Fellowship (569596). R.M.-M. is supported by the Clem and Jones Foundation, the State Government of Queensland, and the NHMRC Boosting Dementia Research Initiative. T.W. is supported by a Discovery Early Career Researcher Fellowship (DE170100546). M.J.R. is supported by a SpinalCure Australia Career Development Fellowship. We thank members of the Meunier and Coulson laboratories for technical assistance; Rumelo Amor for expert help with microscopy; Alan Ho, Pranesh Padmanabhan, and Tristan Wallis for expert help with statistical analysis; Rodrigo Medeiros and Judit Camats for providing frozen mouse brain samples; Nick Valmas for graphic design; Rowan Tweedale for critical reading and editing of the manuscript; UniQuest and the Queensland Emory Drug Discovery Initiative team for commercial insights and technical assistance; and the technical staff of the University of Queensland's Biological Resources and the Queensland Brain Institute animal facility for maintaining the various mouse lines used in this study.

B.V. is a consultant for Karus Therapeutics (Oxford, UK), iOnctura (Geneva, Switzerland), and Venthera (Palo Alto, California) and received speaker fees from Gilead (Foster City, California). The remaining authors declare no competing financial interests.

*N.M. and L.Q. contributed equally to this work.

Correspondence should be addressed to Frédéric A. Meunier at f.meunier@uq.edu.au or Elizabeth J. Coulson at e.coulson@uq.edu.au.

https://doi.org/10.1523/JNEUROSCI.0674-19.2019

Copyright $\odot 2019$ the authors with the effects of inhibiting this isoform in the context of neurological disorders also remaining unexplored.

In this study, we crossed the double-transgenic APP/PS1 mouse model of AD (Jankowsky et al., 2004) with the PI3Kp $110 \delta^{\mathrm{D} 910 \mathrm{~A}}$ mouse line (hereafter referred to as $\delta^{\mathrm{D} 910 \mathrm{~A}}$ ), in which the endogenous PI $3 \mathrm{~K} \delta$ is rendered kinase-dead via the germline introduction of a point mutation in its ATP-binding site (Okkenhaug et al., 2002), to generate the APP/PS1/ $\delta^{\mathrm{D} 910 \mathrm{~A}}$ composite strain. Using genetic and pharmacological approaches in vitro and in vivo, we then investigated the effect of inhibiting PI $3 \mathrm{~K} \delta$ on the trafficking of APP in neurons and the development of AD neuropathology in APP/PS1 and APP/PS1/ $\delta^{\mathrm{D} 910 \mathrm{~A}}$ mice. Our results highlight novel roles for PI $3 \mathrm{~K} \delta$ in mediating the accumulation of $\mathrm{A} \beta$ plaques and the concomitant chronic inflammation, opening potential therapeutic opportunities to interfere with $\mathrm{AD}$ progression through the targeting of PI $3 \mathrm{~K} \delta$ activity.

\section{Materials and Methods}

Animals. APP/PS1 transgenic mice (Jax Mice Database strain B6C3 Tg (APPswe, PSEN1dE9) 85Dbo/Mmjax; stock \#34829-JAX | APP/PS1) express human APP695 with Swedish mutations (K595N and M596L) and mutant human presenilin 1 carrying the exon-9-deleted variant (Jankowsky et al., 2004). Hemizygous APP/PS1 transgenic males aged 6.5 months were used, together with age-matched nontransgenic littermate controls. Only male mice were used in these studies as gender differences in plaque deposition for this transgenic line have been reported (Burgess et al., 2006). The $\delta^{\mathrm{D} 910 \mathrm{~A}}$ kinase-dead mice were generated by a germline knock-in mutation in the ATP-binding site of p $110 \delta$, as described previously (Okkenhaug et al., 2002). Double transgenic mice were derived from $\mathrm{APP} / \mathrm{PS} 1 \times \delta^{\mathrm{D} 910 \mathrm{~A}}$ and $\mathrm{APP} / \mathrm{PS} 1 / \delta^{\mathrm{D} 910 \mathrm{~A} / \mathrm{WT}} \times \delta^{\mathrm{D} 910 \mathrm{~A} / \mathrm{D} 910 \mathrm{~A}}$ crosses. DNA was extracted from toe samples of each mouse and appropriately digested and genotyped as previously described (Okkenhaug et al., 2002). Mice were housed in a climate-controlled room on a $12 \mathrm{~h}$ light/dark with access to standard chow and water ad libitum. For each genotypic cohort, animals were age-matched based on their week of birth. All experiments were approved by the Animal Ethics Committee at the University of Queensland and conducted in accordance with the Australian Code of Practice for the Care and Use of Animals for Scientific Purposes.

Primary neuronal cultures. Hippocampal neurons were cultured from embryonic day 16 (E16) mice. For live-imaging, neurons were plated onto $35 \mathrm{~mm}$ glass-bottom dishes (Cellvis). For immunocytochemistry, neurons were plated onto $12 \mathrm{~mm}$ coverslips (Thermo Scientific). In both situations, the glass surfaces were coated with poly-L-lysine (SigmaAldrich). Primary neuronal culture was performed as described previously (Joensuu et al., 2017). Briefly, the dissected hippocampi were digested with $0.25 \%$ trypsin-EDTA and DNase I for $20 \mathrm{~min}$ at $37^{\circ} \mathrm{C}$, followed by mechanical trituration. Neurons were then plated in "neuronal plating medium" (Neurobasal medium supplemented with penicillin/streptomycin, 1\% Glutamax, and 10\% FBS), and $4 \mathrm{~h}$ later the medium was changed to "neuronal culture medium" (Neurobasal medium supplemented with penicillin/streptomycin, 1\% Glutamax, and $2 \% \mathrm{~B} 27$ ). The neurons were transfected after $12 \mathrm{~d}$ in vitro (DIV12) using the Lipofectamine 2000 (Invitrogen) reagent, with experiments being performed at DIV14-18.

Plasmids. APP695-GFP was a generous gift from Dr. Olav Andersen (Aarhus Universitet) (Andersen et al., 2005; Schmidt et al., 2007). RFPfused vesicular stomatitis virus membrane glycoprotein (VSVG-RFP) was a generous gift from J.L. Daniotti (Universidad Nacional de Córdoba, Ciudad Universitaria, X5000 HUA Córdoba, Argentina; Keller et al., 2001).

Reagents. CAL-101 was purchased from Active Biochem. A methoxypyridyl substituted quinazoline analogous to Leniolisib (CDZ173) (Compound 12) was synthesized and provided by the Queensland Emory Drug Discovery Initiative (QEDDI, Australia) based on Hoegenauer et al. (2016). Both compounds were dissolved in DMSO (Sigma-Aldrich). 
Live imaging of APP-GFP anterograde carriers. Treatment and live imaging of APP-GFP anterograde carriers was performed on hippocampal neurons at DIV14-18 using a Roper iLas2 microscope (Roper Scientific) (100X). CAL-101 or DMSO $(0.1 \%)$ was added to the neurons, after which they were immediately returned to the incubator for $1 \mathrm{~h} 45 \mathrm{~min}$. Following incubation, the medium was replaced with prewarmed imaging medium $\left(0.5 \mathrm{~mm} \mathrm{MgCl}_{2}, 2.2 \mathrm{~mm} \mathrm{CaCl} 2,5.6 \mathrm{~mm} \mathrm{KCl}, 145 \mathrm{~mm} \mathrm{NaCl}\right.$, $5.6 \mathrm{~mm}$ D-glucose, $0.5 \mathrm{~mm}$ ascorbic acid, $0.1 \% \mathrm{w} / \mathrm{v}$ BSA and $15 \mathrm{~mm}$ HEPES, $\mathrm{pH}$ 7.4). Under the microscope, five axons from five different neurons transfected with APP-GFP were selected and each position was saved using the Multidemensional Acquisition App of MetaMorph software (Molecular Devices). This took $\sim 15 \mathrm{~min}$. Images were then immediately acquired (2500 frames every $100 \mathrm{~ms}$ ). Kymographs were generated for the resulting images using FIJI-ImageJ (Schindelin et al., 2012) and the plugins Multi-Kymograph and Trackmate (Tinevez et al., 2017).

Immunofluorescence staining. For double immunofluorescence labeling of brain tissue, $40 \mu \mathrm{m}$ thickness floating sections were blocked with $5 \%$ normal horse serum (NHS) and $0.1 \%$ Triton X-100 in phosphate buffer saline (PBS) for $1 \mathrm{~h}$. To immunostain microglia and astrocytes, sections were then incubated with anti-Ibal (1:500, Abcam) and antiGFAP (1:500, Abcam) primary antibodies, respectively, in blocking solution overnight at $4^{\circ} \mathrm{C}$. After washing, labeling was visualized by incubating the sections with an appropriate mixture of secondary antibodies (Alexa Fluor 488-conjugated donkey anti-rabbit and Alexa Fluor 647-conjugated donkey anti-goat, respectively; 1:1000; Invitrogen); cell nuclei were stained with 4',6-diamindino-2-phenylindole dihydrochloride (DAPI, 1:5000, Sigma-Aldrich). Sections were then washed, mounted onto Superfrost Plus slides (Lomb Scientific) and coverslipped with fluorescence mounting medium (Dako).

For immunofluorescence labeling of primary cultures, neurons were fixed during 10 min with PBS containing 4\% paraformaldehyde (PFA) and $4 \%$ sucrose, permeabilized for 10 min with PBS containing $0.1 \%$ Triton X-100 and blocked with PBS containing 5\% NHS and 1\% BSA for 1 h. Primary antibodies anti-APP (1:500, Abcam), anti MAP2 (1:1000, Synaptic Systems), anti-NF (1:2000, BioLegend), and anti-GM130 (1: 500 , BD Transduction Laboratories) were diluted in PBS containing 3\% $\mathrm{BSA}$ and incubated overnight at $4^{\circ} \mathrm{C}$. After washing, labeling was visualized by incubating the neurons with an appropriate mixture of secondary antibodies (Alexa Fluor 488-conjugated donkey anti-rabbit and Alexa Fluor 647-conjugated donkey anti-goat, respectively; 1:1000; Invitrogen) diluted into PBS containing 5\% NHS for $1 \mathrm{~h}$. Neurons were mounted with fluorescent mounting medium (Dako).

Thioflavin S staining. For Thioflavin S staining, 40- $\mu \mathrm{m}$-thick floating sections were mounted on slides and left to dry overnight. The following day, the slides were washed in distilled water, incubated in the dark with twice-filtered $0.1 \%$ Thioflavin S (Sigma-Aldrich) solution for $5 \mathrm{~min}$ and then washed with $70 \%$ ethanol followed by distilled water to remove excess stain. Finally, the slides were left to dry and then mounted in fluorescent mounting media (Dako).

Image acquisition, processing, and quantification. The imaging for immunofluorescence microscopy of fixed primary neurons was performed on a Zeiss LSM 510 inverted confocal microscope $(63 \mathrm{x})$ and analyzed with FIJI-ImageJ (Schindelin et al., 2012). For the analysis, 30 to 40 fields (142.86 $\mu \mathrm{m} \times 142.86 \mu \mathrm{m}$ ) each one containing 1 to 2 somas were selected from 2 technical replicate dishes, and 3 independent cultures were used per analysis. The morphology of the axon was derived from masks using the neurofilament channel, and the fluorescence intensity of the APP signal within the masked regions was measured using FIJI-ImageJ. The morphology of the soma was derived from masks using the MAP2 channel, and the degree of colocalization between the APP signal and GM130 signal was measured using the JACoP plug-in of FIJI-ImageJ.

Fluorescence images of labeled brain slices were acquired using an upright Axio Imager microscope equipped with an AxioCam HRc digital camera and AxioVision Microscopy software (Z1; Carl Zeiss). Highresolution mosaic images were compiled from $Z$-stack images obtained using a 20x objective ( 4 optical sections $2 \mu \mathrm{m}$ thick) of the cortex and hippocampus. All images were transposed into a mean intensity projection using the Zeiss AxioVision Microscopy software.
To quantify A $\beta$ plaques, the images were opened in FIJI-ImageJ and the number of plaques in the brain regions of interest (hippocampus and cortex) was counted manually. The boundary of the hippocampus was determined by anatomical landmarks delineated using a brain atlas (Franklin and Paxinos, 2013). To determine the total area covered by plaques, FIJI-ImageJ was used to set an intensity threshold to encapsulate the area of Thioflavin S staining. The number of plaques and the area covered by plaques was averaged across three representative sections per brain at the level of the hippocampus and cortex. The results are expressed as the mean and the SEM for four brains analyzed for each cohort of mice.

To analyze the brain infiltration of astrocytes and microglia, a $Z$ stack of the hippocampus and cortex containing markers for astrocytes (GFAP) and microglia (Iba1) was rendered into 3D using Imaris 7.5 software (Bitplane Scientific Software). The total number of voxels occupied by GFAP or Ibal staining was modeled by creating an automatic isosurface. The volume occupied by GFAP or Iba1 staining was normalized to the volume of the hippocampal or cortical region. This volume was then averaged across three representative sections per brain at the level of the hippocampus and cortex. The results are expressed as the mean and the SEM of four brains analyzed for each cohort of mice.

Tissue lysis and protein quantification. Animals were culled by cervical dislocation. The brain was immediately dissected to isolate the cortex and the hippocampus of both hemispheres. To extract the proteins, the dissected tissue was homogenized in ice-cold lysis buffer $(20 \mathrm{~mm}$ Tris- $\mathrm{HCl}$, 150 mм NaCl, 1 mм EDTA, 1 mm EGTA, 1\% Triton X-100, 1\% Nonidet P-40, Sigma-Aldrich) containing complete protease inhibitors (Roche). Brain tissue homogenates were then centrifuged at $15,000 \mathrm{rpm}$ for $15 \mathrm{~min}$ at $4^{\circ} \mathrm{C}$. The total protein concentration was assessed for each supernatant using the Pierce Bicinchoninic Acid (BCA) Protein Assay Kit (Thermo Scientific) before SDS-PAGE protein separation and analysis by Western blotting.

Analysis of protein expression. Western blotting was used to assess the protein expression levels of TNF $\alpha$, APP, A $\beta 40 / 42$, PSD-95, and Synapsin-1 in the cortex of mice. Samples were prepared by mixing $20 \mu \mathrm{g}$ of protein supernatant with sample buffer $\left(4 \times\right.$ NuPAGE $^{\circledR}$ LDS sample buffer, Invitrogen) and dithiothreitol, followed by denaturing of the sample at $95^{\circ} \mathrm{C}$ for $10 \mathrm{~min}$. Proteins were separated on a NuPAGE ${ }^{\circledR} 12 \%$ Bis-Tris gel (Invitrogen) for TNF $\alpha$, or on a $4-12 \%$ Novex Bis-Tris gel (Life Technologies) for APP and A $\beta 40 / 42$, at $140 \mathrm{~V}$ for 90 min using the Invitrogen XCell SureLock Gel electrophoresis system with 1x NuPAGE 3-(N-morpholino) propane sulfonic acid SDS running buffer (Invitrogen). After separation, proteins were transferred onto a polyvinylidene difluoride membrane at $90 \mathrm{~V}$ for $90 \mathrm{~min}$ submerged in Tris/glycine transfer buffer. The membrane was then blocked in 5\% w/v Diploma skim milk powder in PBS containing 0.1\% Tween-20 (PBST) for $1 \mathrm{~h}$ at room temperature. Membranes were incubated on a rotator overnight at $4^{\circ} \mathrm{C}$ in TNF $\alpha$ primary antibody (1:1000, Abcam) and $\beta$-3-tubulin for a loading control (1:1000, Calbiochem); 6E10 antibody (1:2000, BioLegend) and GAPDH for a loading control (1:4000, Cell Signaling Technology); or PSD-95 antibody (1:1000, Santa Cruz Biotechnology), Synapsin-1 antibody (1:1000, Synaptic Systems) and GAPDH for a loading control (1: 4000, Cell Signaling Technology). After $3 \times 15$ min washes in PBST, the membrane was incubated with the appropriate secondary antibodies in blocking solution (680 Infrared anti-mouse and 800 Infrared anti-rabbit, LI-COR Biosciences). After three washes, the membranes were imaged using the Odyssey Infrared Imaging System (LI-COR Biosciences). Densitometry analysis was conducted using the Odyssey Fc Imaging System and Image StudioTM (LI-COR Biosciences) and FIJI-ImageJ software was used to quantify changes in protein expression.

Measurement of $A \beta$ secretion and metabolic rate in primary neuronal cultures. These experiments were performed independently by QPS Austria. Primary cortical mouse neurons (E18) were isolated using standard protocols and seeded into 24-well (MSD assay; $3 \times 10^{5}$ neurons per well) and 96-well plates (MTT assay; $5 \times 10^{4}$ neurons per well) previously coated with poly-D-lysine. Neurons were cultivated for $7 \mathrm{~d}$ in the presence of the test compound (CAL-101) or vehicle control (DMSO). At DIV4 and DIV6, half of the medium was replaced with fresh culture medium containing CAL- 101 or vehicle (culture medium/0.1\% DMSO). 
A
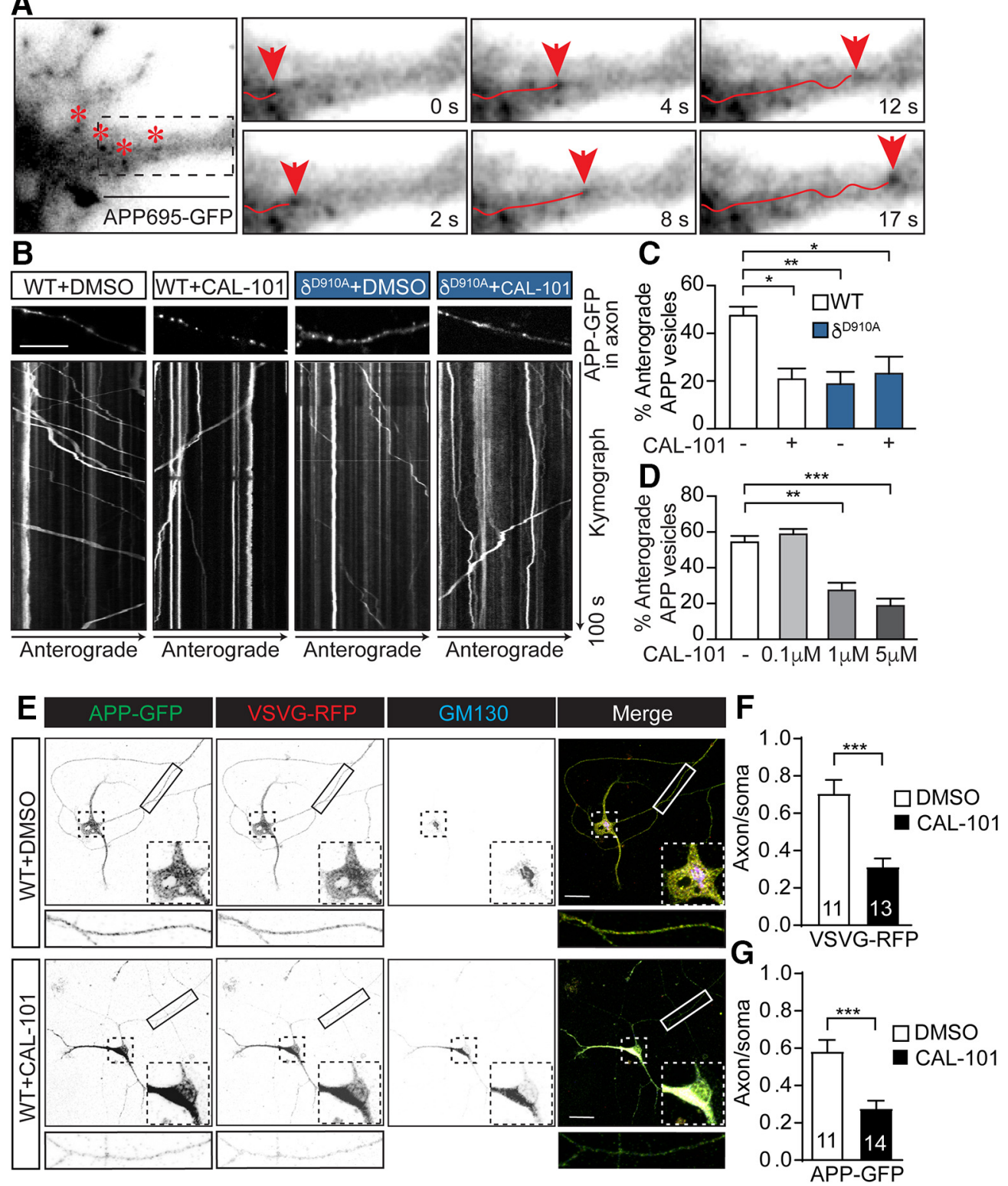

Figure 1. Axonal anterograde trafficking of APP in hippocampal neurons is reduced by pharmacological or genetic inhibition of PI3K $\delta$. $A$, Detail of a hippocampal neuron transfected with APP-GFP. Asterisks represent different APP-containing vesicles. The boxed area is magnified in the right panels. The panels represent images of a time series showing a vesicle containing APP-GFP (arrowhead) moving anterogradely along the axon. $\boldsymbol{B}$, Representative kymographs of APP-GFP-containing vesicles moving along the axons of hippocampal neurons from mice of different genotypes and treated with control vehicle (DMSO) or CAL-101 $(1 \mu \mathrm{M})$ for $2 \mathrm{~h}$. Each analyzed region is shown just above the respective kymograph. C, Quantification of the percentage of anterograde axonally transported APP-positive vesicles in DMSO or CAL-101 $(1 \mu \mathrm{M})$ treated neurons from WT or $\delta^{\mathrm{D} 910 \mathrm{~A}}$ mice. D, Quantification of the percentage of anterograde axonally moving APP-positive vesicles in WT neurons treated with different concentrations of CAL-101. E, Representative images of triple fluorescence immunocytochemistry for APP-GFP (green), VSVG-RFP (red), and GM130 (blue) of WT hippocampal cultures of DIV10 neurons treated with control DMSO (top) or CAL-101 (1 $\mu \mathrm{M})$ (bottom) for $2 \mathrm{~h}$. F, Quantification of the alteration of neuronal trafficking of VSVG-RFP in neurons treated with DMSO or CAL-101 $(1 \mu \mathrm{M})$. G, Quantification of the alteration of neuronal trafficking of APP-GFP in neurons treated with DMS0 or CAL-101 (1 $\mu \mathrm{M})$. The subcellular trafficking was evaluated as the ratio of each protein (APP or VSVG) in axonal compartments to that colocalizing with cis-Golgi GM130-positive structures in the soma. Scale bars, $10 \mu \mathrm{m}$ in $\boldsymbol{A}$ and $\boldsymbol{B}$ and $20 \mu \mathrm{m}$ in $\boldsymbol{E}$. Data are displayed as mean \pm SEM. $n=25-38$ neurons from 3 independent neuronal cultures in $\boldsymbol{C}$ and $\boldsymbol{D}$ and $n=11-14$ neurons in $\boldsymbol{F}$ and $\boldsymbol{G}$; one-way ANOVA followed by Bonferroni's post hoc test comparing each genetic group with its vehicle control (DMSO) and with the WT or APP/PS1 control group (DMSO) in ( and $\boldsymbol{D}$; Student's $t$ test in $\boldsymbol{F}$ and $\mathbf{G}$, ${ }^{*} p<$ $0.05,{ }^{* *} p<0.01,{ }^{* * *} p<0.001$.

On DIV8 (chronic), supernatants were collected and cells were lysed in RIPA buffer (150 mm NaCl, 50 mm Tris- $\mathrm{HCl}$ pH 7.4, 1 mm EDTA, 1\% Nonidet P40, 0.25\% Natriumdeoxycholat, $0.1 \%$ SDS, Protease Inhibitor Cocktail I, Calbiochem). Secreted A $\beta 38,40$ and 42 and intracellular $\mathrm{A} \beta 38,40$ and 42 levels were measured using a commercially available immunosorbent Meso Scale Discovery (MSD) assay kit from Mesoscale Diagnostics, applying 4G8 antibody. The immune assay was performed according to the manual and plates were read on the Sector Imager 2400. Analyte levels were evaluated according to adequate $\mathrm{A} \beta$ peptide stan- dards (MSD) as picograms per milliliter and as absolute signals. Furthermore, the effects of prolonged exposure to the test compound on cell viability and metabolic rate were determined using the MTT assay. MTT solution was added to each well at a final concentration of $0.5 \mathrm{mg} / \mathrm{ml}$. After $2 \mathrm{~h}$, the MTT-containing medium was aspirated. Cells were lyzed in $3 \% \mathrm{SDS}$ and the formazan crystals were dissolved in isopropanol/ $\mathrm{HCl}$. The optical density (OD) was measured with a plate-reader at wavelength $570 \mathrm{~nm}$. The metabolic rate was expressed as the OD. Values were calculated as a percentage of the vehicle control. These experiments were 


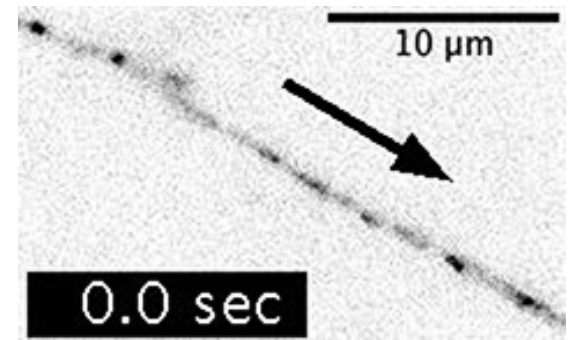

Movie 1. APP-GFP vesicles moving along the axon of hippocampal neuron (DIV14). Video at 100 frames per second (fps), with each frame being acquired every $0.1 \mathrm{~s}$. The arrow indicates the anterograde direction. Images acquired before 60 min treatment with CAL-101 (1 $\mu \mathrm{M})$. Scale bar represents $10 \mu \mathrm{m}$.

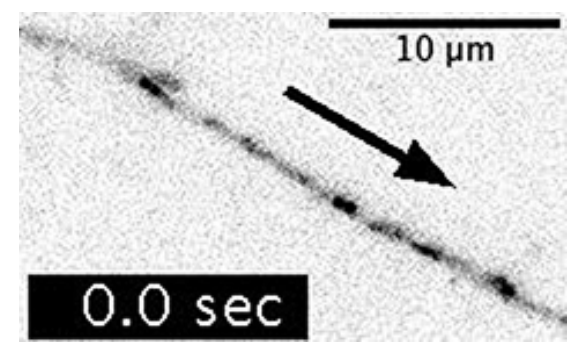

Movie 2. APP-GFP vesicles moving along the axon of hippocampal neuron (DIV14). Video at 100 frames per second (fps), with each frame being acquired every $0.1 \mathrm{~s}$. The arrow indicates the anterograde direction. Images acquired after 60 min treatment with CAL-101 (1 $\mu \mathrm{M})$. Scale bar represents $10 \mu \mathrm{m}$.

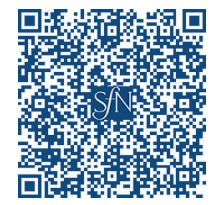

performed in five (acute) or six (chronic) technical replicates and repeated two independent times. Group differences were evaluated by oneway ANOVA followed by Bonferroni's post hoc analysis, comparing all treatment groups to the vehicle control group.

Measurement of $A \beta 42$ from mouse brains. Males and females mice from APP/PS1 and APP/PS1/ $\delta^{\text {D910A }}$ genotypes and 5-7 months old were anesthetized and transcardially perfused with PBS. The cortex was dissected, weighed, and snap frozen with liquid nitrogen. Tissue lysates were prepared by homogenization in 10 volume ( $\mathrm{v} / \mathrm{w}$ ) of RIPA buffer (containing Roche cOmplete protease inhibitor cocktail and PhosSTOP phosphatase inhibitor cocktail and $1 \mathrm{~mm}$ AEBSF) using Precellys Evolution homogenizer (Bertin Technologies). After homogenization, the lysate containing soluble $\mathrm{A} \beta 42$ was collected at $100,000 \times \mathrm{g}$ for $20 \mathrm{~min}$ at $4^{\circ} \mathrm{C}$. To determine the level of total $A \beta 42$ in the brain (containing fibrillary $A \beta 42$ ), the homogenate was mixed with $8.2 \mathrm{~m}$ guanidine/ $82 \mathrm{~mm}$ Tris- $\mathrm{HCl}, \mathrm{pH} 8.0$, and then incubated for $4 \mathrm{~h}$ at room temperature. After diluting the homogenate with cold BSAT-DPBS buffer $\left(0.2 \mathrm{~g} / \mathrm{L} \mathrm{KCl}, 0.2 \mathrm{~g} / \mathrm{L} \mathrm{KH}_{2} \mathrm{PO}_{4}\right.$, $8.0 \mathrm{~g} / \mathrm{L} \mathrm{NaCl}, 1.150 \mathrm{~g} / \mathrm{L} \mathrm{Na}_{2} \mathrm{HPO}_{4}, 5 \%$ BSA and $0.03 \%$ Tween-20, pH 7.4) containing protease inhibitor cocktails, the supernatant was collected after centrifugation at $16,000 \times g$ for $20 \mathrm{~min}$ at $4^{\circ} \mathrm{C}$. The level of $A \beta 42$ in the tissue was assessed by an Amyloid $\beta 42$ Human ELISA Kit (Invitrogen) as per the manufacturer's instructions. The resulting measurements were normalized for tissue weight.

Measurement of TNF $\alpha$ and other cytokine secretion and metabolic rate in primary microglia cultures. These experiments were performed independently by QPS Austria. Primary mouse microglia from newborn pups at postnatal day 1 (P1) to $\mathrm{P} 4$ were isolated using standard protocols and seeded into poly-D-lysine-coated T75 flasks (one pup per flask) in "microglia culture medium" (DMEM supplemented with 10\% FBS, $1 \%$ penicillin/streptomycin, and $2 \mathrm{~mm}$ L-glutamine). The medium was changed every 3-4 $\mathrm{d}$ and cells were cultured for $14 \mathrm{~d}$ before harvesting the microglia by shaking the flasks at $200 \mathrm{rpm}$ at $37^{\circ} \mathrm{C}$ for $2 \mathrm{~h}$. Microglia cells were seeded into uncoated 96 -well plates at $8.2 \times 10^{4}$ cells/well and incubated for $2 \mathrm{~h}$ at $37^{\circ} \mathrm{C}$. The plates were then rocked at $100 \mathrm{rpm}$ for $5 \mathrm{~min}$ to detach the oligodendrocytes. The medium containing the floating oligodendrocytes was discarded and exchanged with fresh medium. Microglial cells were incubated for $2 \mathrm{~d}$ at $37^{\circ} \mathrm{C}$ before lipopolysaccharide (LPS, Sigma-Aldrich) treatment. For the LPS stimulation assay, the culture medium was removed completely $1 \mathrm{~h}$ before the addition of LPS and replaced by "microglia treatment medium" (DMEM supplemented with $5 \% \mathrm{FBS}$ and $2 \mathrm{~mm}$ L-glutamine) containing three different concentrations of "compound 12 " or DMSO $(0.1 \%)$. One hour later, cells were stimulated with control medium or LPS (100 ng/ml). In one condition, dexamethasone (Sigma-Aldrich, $10 \mu \mathrm{M}$ ) was added in parallel to LPS stimulation as an inhibitor of cytokine release. Twenty-four hours after LPS stimulation, the cell supernatants were collected. The levels of TNF $\alpha$, IFN $\gamma$, IL-6, and IL-10 were measured by an immunosorbent assay (U-PLEX Custom Mouse Cytokine, Mesoscale Discovery) according to the manufacturer's instructions and evaluated compared with calibration curves provided in the kit. Results are given as picograms per milliliters or as intensity signal arbitrary units (AUs). The experiment was performed in six technical replicates for all groups and repeated two independent times. The metabolic rate and viability after $24 \mathrm{~h}$ of LPS stimulation of the cultures was determined by the MTT assay as described for the neuronal cultures. Group differences were evaluated by one-way ANOVA followed by Bonferroni's post hoc test comparing all groups with the LPS control group.

Measurement of TNF $\alpha$ and other cytokine secretion in Bv-2 cells. These experiments were performed in collaboration with UniQuest and the Queensland Emory Drug Discovery Initiative (Australia). The murine microglial cell line Bv-2 was thawed and cultivated in "microglia culture medium." For the LPS stimulation assay, $5 \times 10^{4} \mathrm{Bv}^{2}$ cells per well were plated out in a 96-well dish. After $48 \mathrm{~h}$, the medium was changed to "microglia treatment medium" supplemented with CAL-101 at one of three different concentrations or DMSO $(0.1 \%)$. One hour later, the cells were stimulated by the addition of LPS $(10 \mathrm{ng} / \mathrm{ml})$ to the medium. Cells treated with DMSO and LPS served as controls. After $8 \mathrm{~h}$ of stimulation, cell supernatants were collected for cytokine measurement. TNF $\alpha$, IFN $\gamma$, IL-6, IL-10, and IL- $1 \beta$ were measured using specific ELISA plates (https://elisakit.com/) according to the manufacturer's instructions. The experiment was performed in four technical replicates for all groups and repeated three independent times. Group differences were evaluated by one-way ANOVA followed by Bonferroni's post hoc test comparing all groups to the LPS control group.

Morris water maze spatial learning and memory test. Animals were handled for two days by the experimenter before the initiation of behavioral experiments. The Morris water maze apparatus, consisting of a circular platform $28 \mathrm{~cm}$ high and $10 \mathrm{~cm}$ in diameter, was placed at a fixed location within a $100 \mathrm{~cm}$ diameter bath containing water $\left(21-23^{\circ} \mathrm{C}\right)$ that was colored with nontoxic white paint to a depth of $1.5 \mathrm{~cm}$ over the platform. Mice were released into the bath from two alternating starting points and given four swim trials a day for $5 \mathrm{~d}, 10-15 \mathrm{~min}$ apart, in which they had up to $60 \mathrm{~s}$ to find a hidden platform and remain resting on it for $10 \mathrm{~s}$ before being assisted back into their home cage. Mice failing to find the platform or remain on it for $<10 \mathrm{~s}$ during trials were assisted to do so before being returned to their cages. The animals were then subjected to a single probe test on the sixth day in which the platform was removed and their search strategy was recorded over $60 \mathrm{~s}$. Latency to cross the position where the platform was located (latency to platform) and frequency of crossing the platform position were determined for each probe trial. Videos were recorded using Cyberlink Power Director V5 and analyzed using Ethovision 5 software.

Statistical analysis. All data were analyzed using GraphPadPrism 5 for Mac OS X software (GraphPad Software, Inc). The D'Agostino and Pearson test was used to test for normality. The unpaired two-tailed Student's $t$ test was used for comparison of two groups. For datasets comparing more than two groups, ANOVA followed by Bonferroni's post hoc test were used with corrections for multiple comparisons. Statistical comparisons in cell culture experiments were performed on a per-cell basis, with neurons collected from at least three independent experiments. The neurons in cell culture experiments were randomly selected within the dishes and blindly analyzed. Statistical comparisons of protein expression, his- 

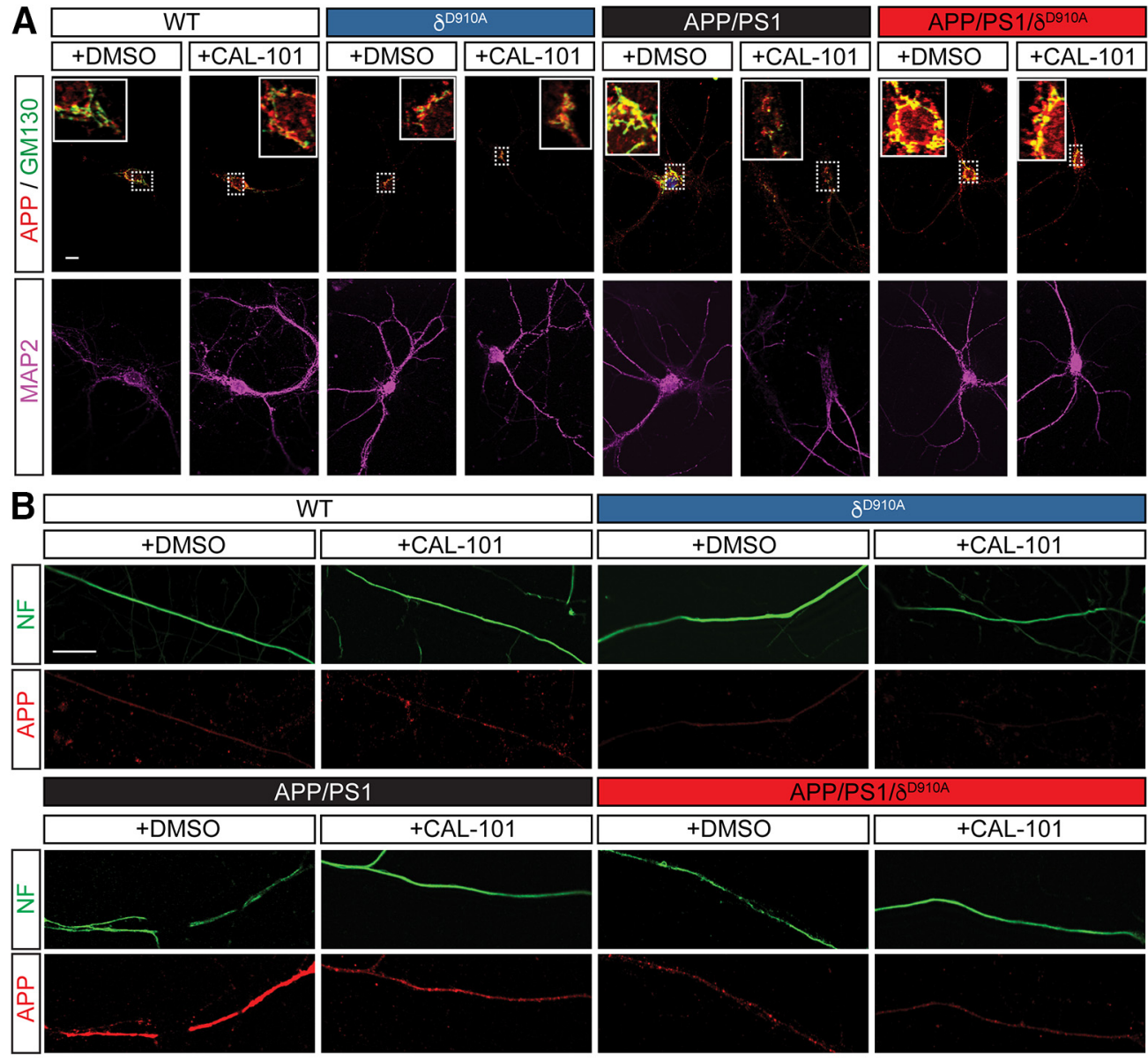

C

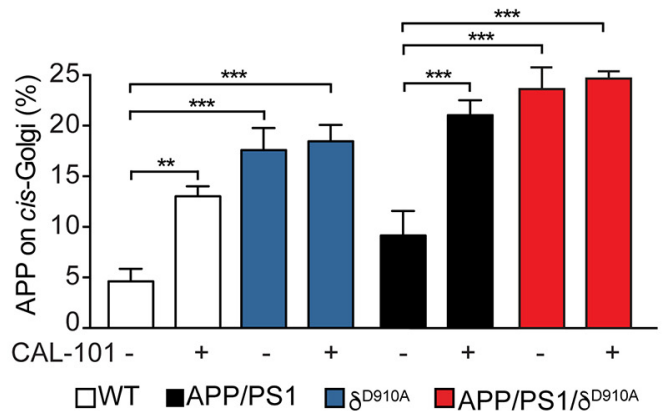

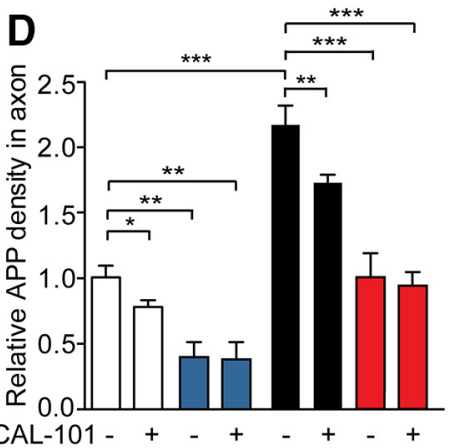

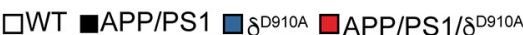

Figure 2. Levels of axonal APP in neurons upon pharmacological or genetic inhibition of PI3K $\delta$. $A$, Representative images of double fluorescence immunocytochemistry for APP (red), GM130 (green), and MAP2 (blue) of cultures of hippocampal neurons from different genotypes treated with DMSO or CAL-101 (1 $\mu \mathrm{M})$ for $2 \mathrm{~h}$. B, Representative images of double fluorescence immunocytochemistry for neurofilament (NF, green) and APP (red) of cultures of hippocampal neurons from different genotypes and treated with DMSO or CAL-101 (1 $\mu \mathrm{M})$ for $2 \mathrm{~h}$. C, Quantification of the retention of APP in the cis-Golgi, as a percentage of the APP signal in GM130-positive structures, in neurons from different genotypes and treated with DMSO or CAL-101 (1 $\mu \mathrm{M})$. D, Quantification of the levels of axonal APP, as the relative APP signal in NF-positive structures, in neurons from different genotypes treated with DMSO or CAL-101 (1 $\mu \mathrm{M})$. Scale bar represents $10 \mu \mathrm{m}$. Data are displayed as mean $\pm \mathrm{SEM}, n=30-46$ neurons from 3 independent neuronal cultures, one-way ANOVA followed by Bonferroni's post hoc test comparing each genetic group with its vehicle control (DMSO) and with the WT or APP/PS1 control group (DMSO), ${ }^{*} p<0.05,{ }^{* *} p<0.01$, ${ }^{* *} p<0.001$.

tological data and animal behavioral experiments were performed on an animal basis, comparing different genotypes. Values are represented as the mean \pm SEM. The tests used are indicated in the respective figure legends.

\section{Results}

PI3K $\delta$ inactivation prevents APP anterograde axonal trafficking in cultured hippocampal neurons

We previously demonstrated that $\mathrm{PI} 3 \mathrm{~K} \delta$ is present in both neurons and microglia (Eickholt et al., 2007; Low et al., 2014). PI3K $\delta$ controls the anterograde post-Golgi trafficking of TNF $\alpha$ in both microglia and macrophages (Low et al., 2010). Based on the notion that TNF $\alpha$ and APP share structural similarities and are both recognized as members of the TNF receptor superfamily (Nikolaev et al., 2009), we investigated whether APP trafficking in neurons could also be regulated by $\mathrm{PI} 3 \mathrm{~K} \delta$. We first transfected cultured mouse hippocampal neurons at DIV12 with APP-GFP to image APP-GFP-positive carriers by time-lapse fluorescence imaging in axons at DIV14-18 (Fig. $1 A$ and Movie 1). To manip- 
ulate PI3K $\delta$ activity, we used a combination of genetic ( $\delta^{\mathrm{D} 910 \mathrm{~A}}$ neurons) and pharmacological approaches, incubating neurons with CAL-101, a selective PI3K $\delta$ inhibitor that is approved for the treatment of B-cell malignancies (Lannutti et al., 2011). The percentage of APP-GFPpositive carriers undergoing anterograde transport decreased dramatically following either genetic or pharmacological inhibition of PI3K $\delta$ (Fig. $1 B-F$ and Movie 2). Treatment with CAL-101 (2 h, $1 \mu \mathrm{M})$ resulted in a selective reduction in the number of vesicles undergoing anterograde trafficking (Fig. 1A). A similar inhibition was found in hippocampal neurons from $\delta^{\mathrm{D} 910 \mathrm{~A}}$ mice (Fig. 1A). Importantly, no additive effect was observed in hippocampal neurons from $\delta^{\mathrm{D} 910 \mathrm{~A}}$ mice treated with CAL-101, ruling out offtarget effects (Fig. 1C). We also tested increasing concentrations of CAL-101 in hippocampal neurons and found a dosedependent inhibition of anterograde trafficking (Fig. 1D). The selectivity of such trafficking was tested using RFP-fused vesicular stomatitis virus membrane glycoprotein (VSVG-RFP), which is a marker for Golgi-derived plasma membrane carriers. When VSVG-RFP was coexpressed with APP-GFP in hippocampal neurons (Fig. $1 E$ ), we found that acute CAL-101 treatment also impacted the anterograde trafficking of VSVG-RFP carriers (Fig. $1 F, G$ ). These results suggest that the axonal anterograde trafficking APP and VSVG are controlled by $\mathrm{PI} 3 \mathrm{~K} \delta$ activity in hippocampal neurons.

We next performed immunostaining of endogenous APP in DIV14 hippocampal neurons from wild-type (WT), $\delta^{\text {D910A, }}$ $\mathrm{APP} / \mathrm{PS} 1$, and $\mathrm{APP} / \mathrm{PS} 1 / \delta^{\mathrm{D} 910 \mathrm{~A}}$ mice, either untreated or treated with CAL-101 $(1 \mu \mathrm{M})$ for $2 \mathrm{~h}$, followed by fixation and coimmunostaining for APP and the cisGolgi marker GM130 (Fig. 2A). A significant increase in APP immunoreactivity was detected in GM130-positive structures following treatment of WT and APP/PS1 neurons with CAL-101 (Fig. 2C). Similarly, high levels of colocalization between APP and GM130 were detected in $\delta^{\mathrm{D} 910 \mathrm{~A}}$ and $\mathrm{APP} / \mathrm{PS} 1 / \delta^{\mathrm{D} 910 \mathrm{~A}}$ hippocampal neurons (Fig. $2 A$ ). Consistent with previous observations, CAL-101 did not induce a detectable additive effect in neurons derived from $\delta^{\mathrm{D} 910 \mathrm{~A}}$ mice (Fig. 2C).

Additional analysis of endogenous APP immunoreactivity in axons (stained with neurofilament) from these neurons showed that CAL-101 reduced the density of APP staining along the axons of WT and APP/PS1 neurons. The APP axonal immunostaining signal was also lower in $\delta^{\mathrm{D} 910 \mathrm{~A}}$ neurons and no further decrease in intensity was observed upon treatment with CAL-101. Similar results were obtained in APP/PS1/ $\delta^{\text {D910A }}$ neurons (Fig. $2 B, D$ ).

D ***** $p<0.0001$.
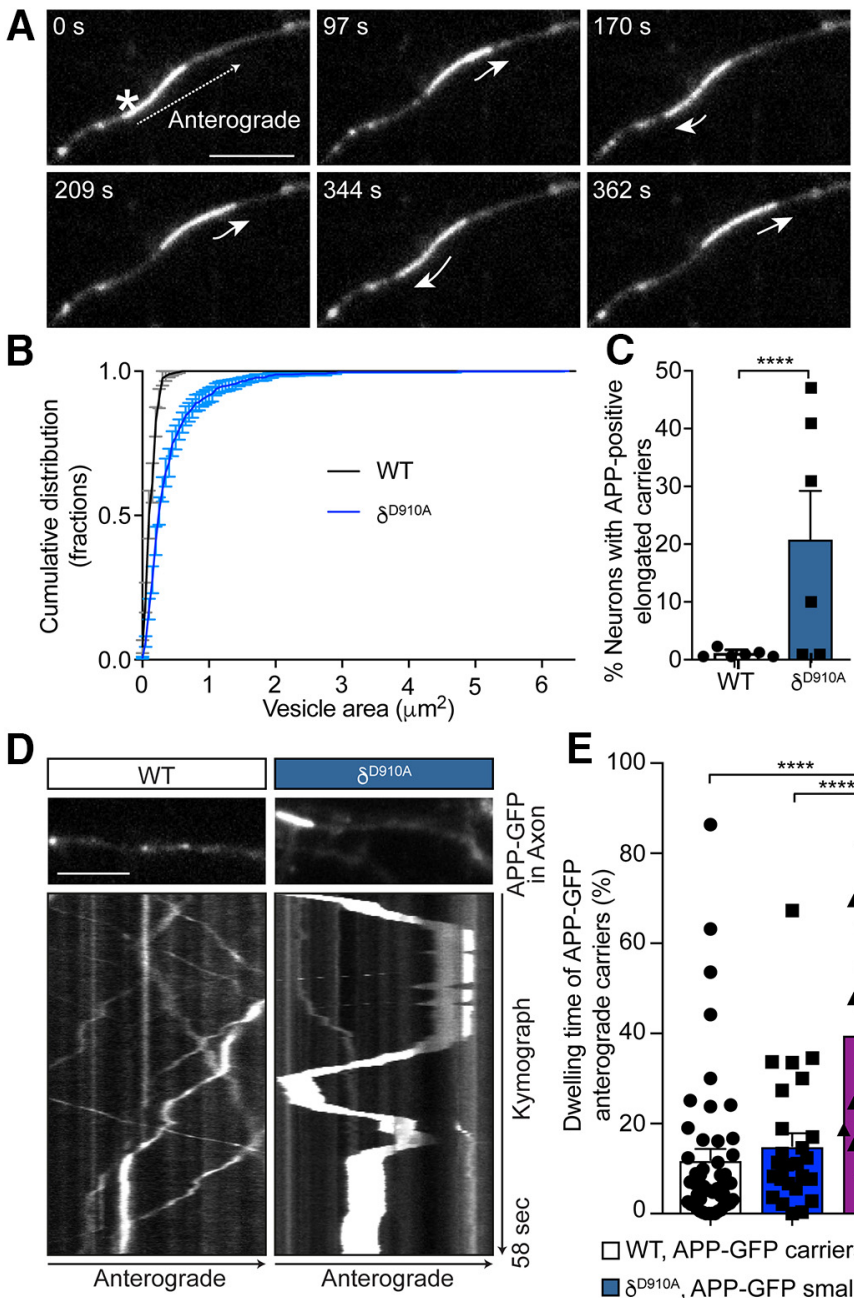

$\mathbf{E}_{100}$

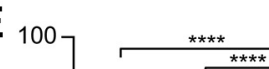

Figure 3. PI $3 K \delta$ inhibition leads to the formation of tubular APP-positive carriers with altered mobility parameters. $\boldsymbol{A}$, Representative time series of hippocampal neurons from $\delta^{\text {D910A }}$ mice transfected with APP-GFP showing an elongated tubular-like carrier containing APP-GFP (asterisk) moving anterogradely along the axon. The short arrows represent changes in movement direction. $\boldsymbol{B}$, Cumulative frequency distribution of the areas of APP-positive carriers from WT or $\delta^{D 910 A}$ neurons. C, Quantification of percentage of neurons containing tubular APP-GFP cargoes in neurons from WT or $\delta^{\text {D910A }}$ mice. $D$, Representative kymographs of APP-GFP-containing carriers moving along axons of hippocampal neurons from WT or $\delta^{\mathrm{D} 910 \mathrm{~A}}$ mice. Each analyzed region is shown just above the respective kymograph. $\boldsymbol{E}$, Quantification of the percentage of dwelling time relative to the total trafficking time in anterograde carriers from WT neurons and small anterograde carriers from $\delta^{\mathrm{D} 910 \mathrm{~A}}$ neurons, and in large tubular anterograde carriers from $\delta^{\mathrm{D} 910 \mathrm{~A}}$ neurons. The dwelling time is defined as the time the carriers spent with an instant speed between 0 and $0.7 \mu \mathrm{m} / \mathrm{s}$. Scale bar represents $5 \mu \mathrm{m}$. Data are displayed as mean $\pm \mathrm{SEM}$; in $\boldsymbol{B}, n=600-800$ carriers from 12-16 neurons from 3 independent neuronal cultures; in $C, n=6$ independent neuronal cultures with $10-27$ neurons analyzed in each experiment; $n=27-50$ carriers from 10 neurons. Student's t test in $C$ and one-way ANOVA in $\boldsymbol{E}$, followed by Bonferroni's post hoc test comparing all groups,

A more detailed evaluation of axonal APP-GFP carriers from $\delta^{\text {D910A }}$ hippocampal neurons revealed the presence of highlyelongated tubular cargoes displaying back-and-forth mobility (Fig. 3A and Movie 3). Whereas the average diameter of APPcontaining vesicles in WT neurons was $0.46 \mu \mathrm{m}$, the average length of these tubular carriers was $2.42 \mu \mathrm{m}$, reaching up to 15 $\mu \mathrm{m}$ for the longest ones, increasing the total area occupied by the carriers from 0.25 to $3 \mu \mathrm{m}^{2}$ (Fig. $3 B$ ). These long tubular APP carriers were found in $20 \%$ of neurons from $\delta^{\mathrm{D} 910 \mathrm{~A}}$ animals, whereas only slightly elongated APP carriers were found in $1 \%$ of WT neurons (Fig. 3C). Interestingly, the tubular carriers from $\delta^{\mathrm{D} 910 \mathrm{~A}}$ neurons represented $53.9 \%$ of the APP-positive total population (Fig. $3 B$ ). The $2 \mathrm{~h}$ treatment of WT neurons with CAL- 


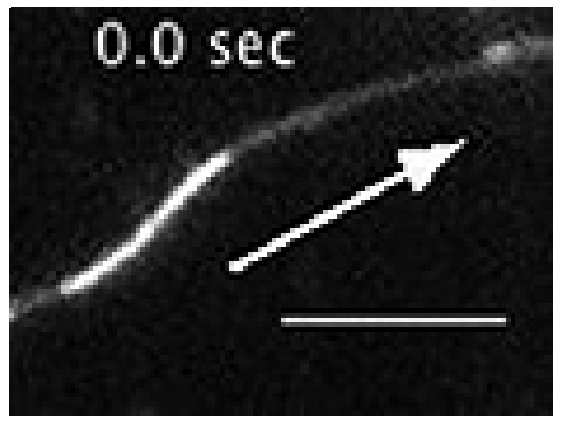

Movie 3. APP-GFP tubular vesicles moving along the axon of a hippocampal neuron (DIV18). Video at 100 frames per second (fps), with each frame being acquired every $0.1 \mathrm{~s}$. The arrow indicates the anterograde direction. Scale bar represents $5 \mu \mathrm{m}$.

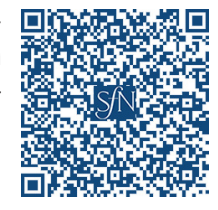

$101(1 \mu \mathrm{M})$ also produced elongated carriers, but only in some neurons (data not shown), suggesting that prolonged PI3K $\delta$ inhibition is required for the formation of these structures. Kymograph analysis of the anterograde tubular carriers revealed a predominant back-and-forth mobility, with a $40 \%$ increase in the dwelling time (Fig. $3 D, E$ ). These results suggest that APP trafficking is dramatically impacted by PI3K $\delta$ inhibition, which likely reduces the downstream processing of APP as it is uncertain whether these carriers can reach their final destination at the nerve terminals.

Collectively, these data suggest that PI $3 \mathrm{~K} \delta$ activity is critical for the anterograde axonal trafficking of APP from the Golgi to presynaptic nerve terminals, and that blocking $\mathrm{PI} 3 \mathrm{~K} \delta$ activity prevents this trafficking and leads to APP accumulation in the Golgi apparatus.

\section{PI3K $\delta$ deficiency attenuates $A \beta$ levels and plaque burden in APP/PS1 mice}

Pathological proteolysis of APP results in the accumulation of $\mathrm{A} \beta$, which is secreted from neurons. To test whether altered APP trafficking affects $A \beta$ formation, we measured the levels of secreted $A \beta 1-38, A \beta 1-40$ and $A \beta 1-42$ in WT primary mouse cortical neurons (Fig. $4 A, B$ ). Treatment with CAL-101 (7 d) impacted on $A \beta 1-40$ and $A \beta 1-42$ secretion at the highest dose tested $(1 \mu \mathrm{M})$ (Fig. $4 A)$. However, we did not detect any difference in $\mathrm{A} \beta$ levels from total lysates (Fig. $4 B$ ). It is worth noting that CAL-101 treatment also slightly reduced the metabolic rate of neurons (Fig. 4C). We next analyzed the effect of PI3K $\delta$ inactivation in vivo. Measurement of synaptic markers indicated, first of all, that PI $3 \mathrm{~K} \delta$ inactivation does not significantly affect the integrity of the synapses (Fig. $5 A-C$ ). We next measured the levels of APP, as well as soluble and insoluble A $\beta 1-$ 40/42 peptides in cortical lysates from 6- to 7-month-old mice (Fig. 5D-G). This revealed slightly reduced levels of total APP in $\mathrm{APP} / \mathrm{PS} 1 / \delta^{\mathrm{D} 910 \mathrm{~A}}$ mice compared with APP/PS1 mice (Fig. $5 E$ ), and a complete blockade of $A \beta 1-40 / 42$ production and accumulation in PI3K $\delta$-deficient APP/PS1 mice (Fig. $5 F, G$ ).

Having established that blocking PI3K $\delta$ activity affects both APP trafficking and A $\beta$ secretion, we next assessed whether these changes led to a reduction in the plaque load. APP/PS1 mice show plaque deposition throughout the cortex and hippocampus as early as 4-6 months of age (Edwards et al., 2014), which was confirmed by staining 6.5-month-old brains for aggregated $\mathrm{A} \beta$ deposition using Thioflavin S. Specifically, hippocampal sections from APP/PS1 animals contained a significant number of Thioflavin S-positive deposits, whereas no plaques were observed in brain sections from either age-matched WT or $\delta^{\mathrm{D} 910 \mathrm{~A}}$ mice (Fig. $6 A)$. Strikingly, both the number and size of the Thioflavin $S$-positive plaques were significantly reduced in the hippocampus of APP/PS1/ $\delta^{\mathrm{D} 910 \mathrm{~A}}$ mice (Fig. $6 \mathrm{~B}, C$ ). Although we did not detect a significant reduction on plaque size in the cortex, there was a $75 \%$ reduction in plaque number in cortical sections (Fig. $6 D$ ) of $\mathrm{APP} / \mathrm{PS} 1 / \delta^{\mathrm{D} 910 \mathrm{~A}}$ mice compared with APP/PS1 animals (Fig. $6 E, F)$. The statistical power of the results is specified in the Fig. 6-1, available at https://doi.org/10.1523/JNEUROSCI.0674-19. 2019.f6-1. PI3K $\delta$ inactivation on plaque size between the cortex and hippocampus could be a reflection of the intrinsically distinct spatial patterns of $A \beta$ deposition in different regions of the brain (Bero et al., 2011; Whitesell et al., 2019). Furthermore, amyloid plaque levels are also directly affected by $\mathrm{A} \beta$ degradation and clearance from the brain tissue by microglia. The PI3K/Akt pathway is specifically involved in microglia migration (Horvath and DeLeo, 2009), and PI3K $\delta$ itself is involved in controlling the secretion of TNF $\alpha$ from microglia (Low et al., 2014). Thus, local alterations of $\mathrm{A} \beta$ clearance by microglial cells could also partially explain the brain area-specific effect in plaque size.

\section{PI3K $\delta$ activity controls TNF $\alpha$ levels and brain gliosis in APP/ PS1 mice}

TNF $\alpha$ is increased in patients with AD (Tarkowski et al., 2003). We therefore next investigated the effect of PI3K $\delta$ on the immune response associated with $\mathrm{AD}$. Pharmacological inactivation of PI3K $\delta$ with CAL-101 dose-dependently reduced TNF $\alpha$ secretion by murine microglia-derived Bv2 cells (Fig. 7A), consistent with previous results in primary murine microglia (Low et al., 2014). A different potent PI3K $\delta$ inhibitor generated by Novartis, a methoxypyridyl substituted quinazoline analogous to Leniolisib (CDZ173), hereafter named "compound 12" (Hoegenauer et al., 2016), induced similar effects to CAL-101 in primary microglia (Fig. $7 B$ ), without affecting the cells' metabolic rate (Fig. $7 C$ ). We also evaluated the effect of PI $3 \mathrm{~K} \delta$ inhibition on the release of other proinflammatory (IL- $1 \beta$, IFN $\gamma$, IL-6) and anti-inflammatory (IL-6, IL-10) cytokines by Bv2 cells (Fig. 7 E, G,I) and primary microglia (Fig. $7 D, F, H, J$ ). None of these cytokines was affected to the same extent as TNF $\alpha$ by pharmacological PI3K $\delta$ inhibition in either of the cellular systems, suggesting some level of specificity for $\mathrm{PI} 3 \mathrm{~K} \delta$ in regulating $\mathrm{TNF} \alpha$ release.

We next determined the impact of PI3K $\delta$ deficiency on TNF $\alpha$ levels in APP/PS1 mice, measured by Western blotting of brain lysates from 6.5-month-old mice (Fig. $7 \mathrm{~K}$ ). In accordance with previous results from animal models (Jin et al., 2008), significantly higher levels of TNF $\alpha$ were detected in APP/PS1 mice than in WT animals (Fig. 7L). This increase was virtually abolished in $\mathrm{APP} / \mathrm{PS} 1 \times \delta^{\mathrm{D} 910 \mathrm{~A}}$ mice, with comparable TNF $\alpha$ levels obtained in lysates from age-matched WT and $\delta^{\mathrm{D} 910 \mathrm{~A}}$ mice (Fig. $7 \mathrm{~L}$ ). These data demonstrate that the high TNF $\alpha$ levels in the APP/PS1 AD mouse model can be normalized by $\mathrm{PI} 3 \mathrm{~K} \delta$ inactivation.

We then further explored whether the expression levels of TNF $\alpha$ also correlated with the level of overall inflammation in the brain. Increased numbers of microglia (Iba1-positive cells) and astrocytes (GFAP-positive cells) were found in APP/PS1 mice compared with WT, $\delta^{\mathrm{D} 910 \mathrm{~A}}$, and $\mathrm{APP} / \mathrm{PS} 1 / \delta^{\mathrm{D} 910 \mathrm{~A}}$ mice, in both the hippocampus (Fig. $8 A-C$ ) and cortex (Fig. $8 D-F$ ). A 75\% reduction in the relative staining volume of microglia and astrocytes was found within the hippocampus of APP/PS1 $/ \delta^{\mathrm{D} 910 \mathrm{~A}}$ mice compared with their APP/PS1 counterparts (Fig. $8 B, C$ ). The statistical power of the results is specified in the Fig. 8-1, available at https://doi.org/ 


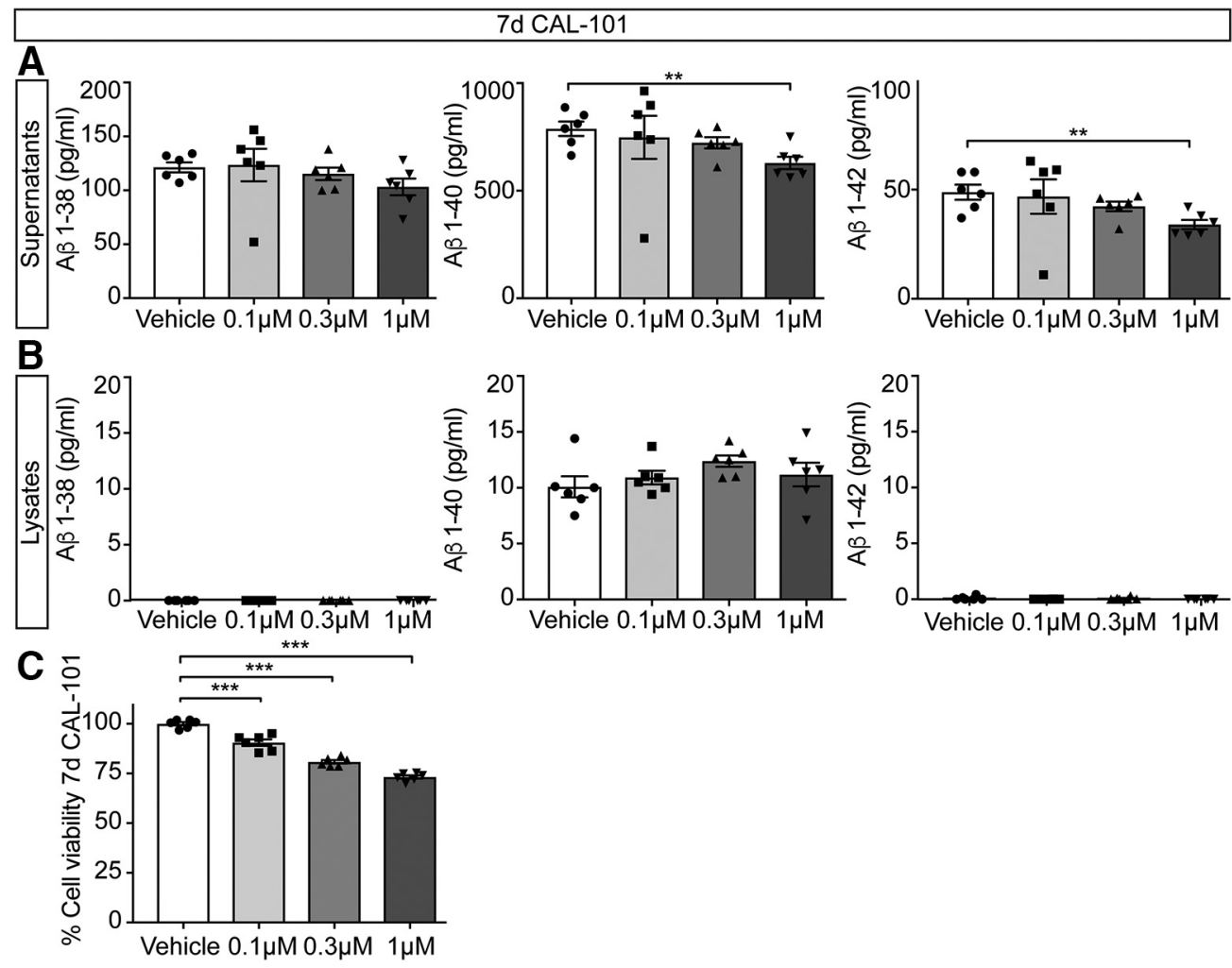

Figure 4. Impact of pharmacological PI3K $\delta$ inactivation on $A \beta$ levels in primary neuronal cell cultures. $A, B$, Primary mouse cortical neurons were treated with $C A L-101(1 \mu \mathrm{M})$ for $7 \mathrm{~d}$. At DIV8, secreted and intracellular $A \beta 1-38, A \beta 1-40$, and $A \beta 1-42$ were measured in supernatants $(\boldsymbol{A})$ and lysates $(\boldsymbol{B})$, respectively. Results are expressed as picograms per milliliter. C, Primary mouse cortical neurons were treated with vehicle (DMSO) or CAL-101 $(0.1,0.3$ and $1 \mu \mathrm{m})$ for $7 \mathrm{~d}$. On DIV8, neurons were subjected to the MTT assay of cell viability. Data are displayed as mean \pm SEM, $n=5-6$ in $\boldsymbol{A}$ and $\boldsymbol{B}, n=6$ in $\boldsymbol{C}$. One-way ANOVA followed by Bonferroni's post hoc test comparing all groups with the vehicle control group in $\boldsymbol{A}-\boldsymbol{C}$, ${ }^{* *} p<$ $0.01,{ }^{* * *} p<0.001$.

10.1523/JNEUROSCI.0674-19.2019.f8-1. significant difference between the APP/PS1 $/ \delta^{\mathrm{D} 910 \mathrm{~A}}$ mice and age-matched WT or $\delta^{\mathrm{D} 910 \mathrm{~A}}$ control groups, indicating full penetrance of the phenotypic rescue in the $\mathrm{APP} / \mathrm{PS} 1 / \delta^{\mathrm{D} 910 \mathrm{~A}}$ mice.

\section{Inactivation of PI3K $\delta$ activity increases the survival of APP/} PS1 mice and prevents cognitive dysfunction

Having established that PI $3 \mathrm{~K} \delta$ inhibition affects both the formation of amyloid plaques and the neuroinflammation response associated with $\mathrm{AD}$ progression, we next tested whether the cognitive impairment associated with this $\mathrm{AD}$ model was alleviated. Given that APP/PS1 mice suffer from premature death at the time at which $\mathrm{A} \beta$ begins to be deposited as plaques (Minkeviciene et al., 2009), we also assessed whether survival was altered in the absence of PI $3 \mathrm{~K} \delta$ activity. Interrogation of colony breeding and maintenance data revealed that $42.7 \%$ (56 of 131) of APP/PS1 mice had died at the $210 \mathrm{~d}$ time point. In contrast, only $3 \%$ (3 of 100) APP/PS1 $/ \delta^{\mathrm{D} 910 \mathrm{~A}}$ mice had succumbed by this age, demonstrating a decrease in the premature mortality of the APP/PS1 mice in response to $\mathrm{PI} 3 \mathrm{~K} \delta$ inactivation (Fig. 9A).

We then evaluated the cognitive impairment associated with $\mathrm{AD}$ progression using the Morris water maze spatial navigation task. APP/PS1 mice present synaptic and memory deficits at 3-6 months of age, concomitant with an increase in amyloid deposition (Trinchese et al., 2004). Nontransgenic WT mice and $\delta^{\text {D910A }}$ controls, in line with previously published data (Eickholt et al., 2007), learned to navigate to the platform within a 5-day training period using a direct navigation strategy (Janus, 2004) (Fig. 9B), and displayed a preference for the original platform location dur- ing the probe trial (Fig. 9B). In contrast, 6.5-month-old APP/PS1 mice displayed significant deficits in performance during the acquisition phase of the Morris water maze (Fig. 9B). The strong cognitive impairment of the APP/PS1 mice was also evident from their inability to remember the position of the submerged platform during the probe trial (i.e., time spent in target area) (Fig. 9C). On average, APP/PS1 mice took three times longer to pass over the learned location of the platform compared with WT or $\delta^{\text {D910A }}$ mice (Fig. 9D); they also crossed the platform position less often than controls during the probe trial (Fig. 9E). Strikingly, the cognitive deficits observed in the APP/PS1 mice were completely absent in $\mathrm{APP} / \mathrm{PS} 1 / \delta^{\mathrm{D} 910 \mathrm{~A}}$ mice. On average, $\mathrm{APP} / \mathrm{PS} 1 / \delta^{\mathrm{D} 910 \mathrm{~A}}$ mice found the escape platform in a time that was equivalent to that of WT and $\delta^{\mathrm{D} 910 \mathrm{~A}}$ mice during training sessions, and they performed equally well as controls in all analyzed parameters of the probe trial (Fig. 9C-E). Together, these results demonstrate that the impairment in spatial learning and memory displayed by $\mathrm{APP} / \mathrm{PS} 1$ mice can be rescued by $\mathrm{PI} 3 \mathrm{~K} \delta$ inactivation. A proposed model for the regulation of APP and TNF $\alpha$ trafficking by PI3K $\delta$ in neurons and microglia is illustrated in Figure $9 F$.

\section{Discussion}

Here, we show that inactivation of $\mathrm{PI} 3 \mathrm{~K} \delta$ acts on both neurons and microglia to prevent anterograde post-Golgi trafficking of APP and TNF $\alpha$, respectively. Both APP trafficking and TNF $\alpha$ mediated neuroinflammation are critically involved in neurodegenerative diseases such as AD. By simultaneously targeting these pathways, we demonstrate that, compared with APP/PS1 mice, $\mathrm{APP} / \mathrm{PS} 1 / \delta^{\mathrm{D} 910 \mathrm{~A}}$ mice exhibit dramatically reduced $\mathrm{A} \beta$ levels, $\mathrm{A} \beta$ 

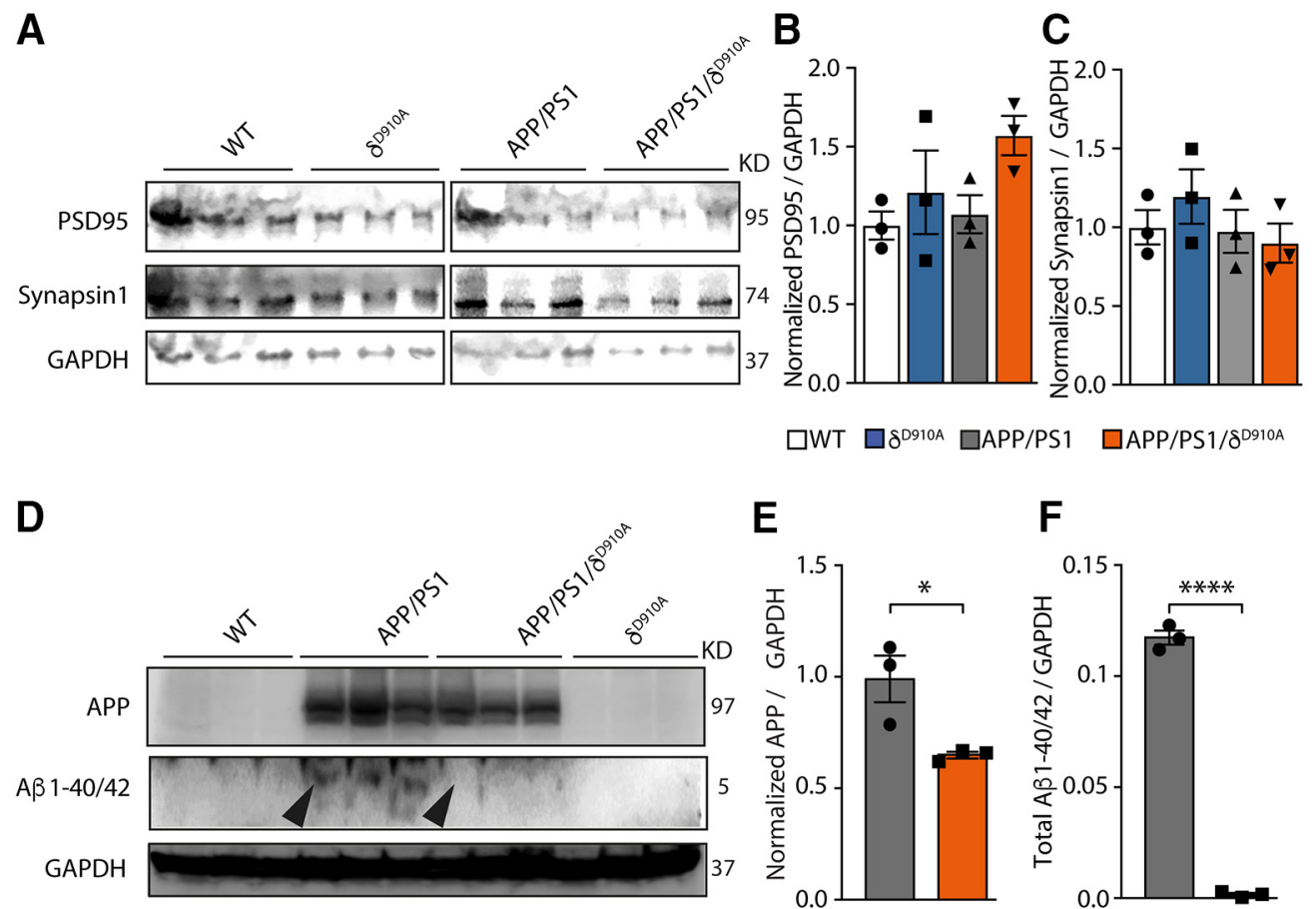

$\mathbf{F}$
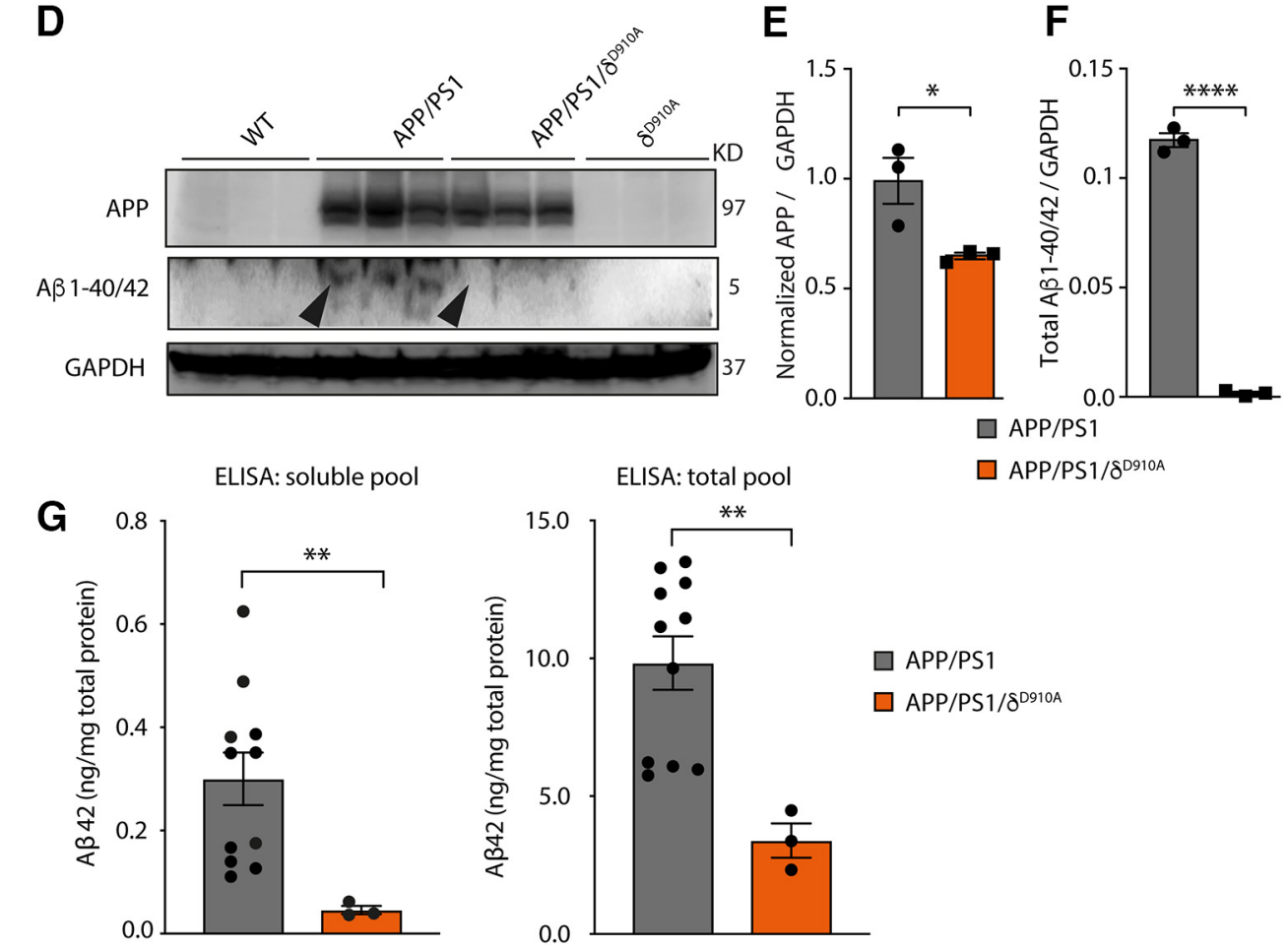

Figure 5. Impact of genetic PI3K $\delta$ inactivation on A $\beta$ and APP levels in brains of APP/PS1 mice. $A$, Representative Western blot of PSD-95 and Synapsin- 1 from brain extracts prepared from a different cohort of 12-month-old mice of indicated genotypes (3 animals per group). $\boldsymbol{B}$, Densitometric measurements of PSD-95 normalized to GADP levels and to the average level obtained in WT mice. C, Densitometric measurements of Synapsin-1 normalized to GADP levels and to the average level obtained in WT mice. $D$, Representative Western blot of APP and A $31-40 / 42$ from brain extracts prepared from the same 12-month-old cohort of mice. $E$, Densitometric measurements of APP normalized to GADP levels and to the average level obtained in APP/PS1 mice. $F$, Densitometric measurements of A $\beta 1-40 / 42$ normalized to GADP levels. G, Quantification of the amount of total and soluble A $\beta 42$ in cortical lysates of APP/PS1 and APP/PS1/ $\delta^{\mathrm{D} 910 \mathrm{~A}}$ mice by ELISA. The data of both genders of APP/PS1 were combined. No significant differences were found between males and females ( $p=0.7922$, data not shown). Data are displayed as mean \pm SEM, $n=3$ in $\boldsymbol{B}-\boldsymbol{D}$ and $\boldsymbol{F}, n=11$ and 3 mice in $\boldsymbol{G}$. One-way ANOVA followed by Bonferroni's post hoc test comparing all groups with the WT group in $\boldsymbol{B}$ and $\boldsymbol{C}$. Student's $t$ test in $\boldsymbol{E}-\boldsymbol{G},{ }^{*} p<0.05$, ${ }^{* *} p<0.01$, $* * * * 00.0001$.

plaque number and size, as well as significant reductions in gliosis and TNF $\alpha$ levels, with complete protection from early cognitive impairment.

Because of its importance in immune signaling, PI3K $\delta$ is considered an important therapeutic target in the treatment of inflammation and autoimmunity (Okkenhaug et al., 2002). Based on its high expression in leukocytes, it is also a target in hematological malignancies (Lampson and Brown, 2017), including chronic lymphocytic leukemia (Furman et al., 2014). Compared with leukocytes, PI3K $\delta$ is also expressed at moderate levels in neurons (Eickholt et al., 2007; Low et al., 2014), and we demonstrate here that PI3K $\delta$ inhibition blocks APP anterograde trafficking in hippocampal neurons. Interestingly, the elongated tubular shape of some axonal APP carriers observed in $\delta^{\text {D910A }}$ neurons resembles the tubular TGN-derived TNF $\alpha$-containing cargoes described in macrophages in response to PI3K $\delta$ inhibition (Low et al., 2010). These results therefore suggest that PI3K $\delta$ might also be involved in the fission machinery required at the TGN for the exit of APP-containing cargoes in neurons. Although the basis of the commonality of action of PI3K $\delta$ on TNF $\alpha$ and APP is currently unknown, it is important to note that PI $3 \mathrm{~K} \delta$ is expressed in the Golgi of macrophages (Low et al., 2010), microglia, and neurons (Low et al., 2014). Like TNF $\alpha$, APP is a type I transmembrane protein that is synthesized at the endoplasmic reticulum and then undergoes complex intracellular trafficking via the TGN, going through the secretory pathway and endocytic, and recycling routes, in the neuronal soma, dendrites and axons (Muresan and Ladescu Muresan, 2015). In addition, APP and $\mathrm{TNF} \alpha$ share structural similarities and APP has been shown to bind the TNF receptor superfamily member Death Receptor 6 
(DR6) (Nikolaev et al., 2009). This common structural and trafficking pathway is likely to underpin the high sensitivity of both APP and TNF $\alpha$ trafficking to PI3K $\delta$ inhibition.

It was not only APP axonal anterograde trafficking that was significantly reduced by PI $3 K \delta$ inhibition; the secretion of $\mathrm{A} \beta$ peptides was also reduced after pharmacological inhibition of PI3K $\delta$ in WT cultured neurons, with dramatically reduced levels of $A \beta 1-40 / 42$ toxic peptides and $\mathrm{A} \beta 42$ fibrils in vivo in the brains of 6- to 7-month-old APP/PS1/ $\delta^{\mathrm{D} 910 \mathrm{~A}}$ mice compared with age-matched APP/PS1 animals. Although inhibition of $\mathrm{PI} 3 \mathrm{~K} \delta$ activity is unlikely to have a direct effect on tau phosphorylation and inclusion, the protection afforded by reducing $\mathrm{APP}$ processing, $\mathrm{A} \beta$ release, and plaque formation might provide a protective environment that reduces tau hyperphosphorylation. However, such protection is unlikely to prevent from tauopathies mediated by tau mutations that are driving toxicity. Further experiments would be required to evaluate these effects. In summary, our data strongly suggest that accumulation of $A \beta 1-40 / 42$ in the $A D$ brain model used is greatly dampened by $\mathrm{PI} 3 \mathrm{~K} \delta$ inhibition.

The level of amyloid plaques is a consequence of a fine balance between the secretion of toxic $A \beta$ peptides, their oligomerization and deposition, and their degradation and clearance from the brain by microglia (Bates et al., 2009). Microglia have a complex role in amyloid plaque formation. In the early stages of $\mathrm{AD}$, microglia accumulate in the vicinity of developing amyloid plaques and exposure to extracellular fibrillary $\mathrm{A} \beta$ converts these immune cells into an "activated" phenotype (Ferrera et al., 2014). A $\beta$-activated microglia show enhanced phagocytosis and clearance of plaques (Bolmont et al., 2008). Furthermore, a reduction in the early accumulation of microglia at the site of inflammation in $\mathrm{AD}$ brains hastens the progression of the disease (El Khoury et al., 2007). However, microglia also have detrimental activities in $\mathrm{AD}$, including the exacerbation of neurotoxic inflammatory signals (Colonna and Butovsky, 2017). The initial low, basal level of TNF $\alpha$ release drives microglia to clear and eradicate plaques (Viel et al., 2001) without enabling the activation of deleterious chronic inflammation. However, at later stages of disease, excess TNF $\alpha$ levels in the brain in response to amyloid aggregates and fibrils can inhibit the microglial clearance of $A \beta$ (Hickman et al., 2008), inducing surrounding astrocytes into a toxic "A1" state that causes neuronal death (Liddelow et al., 2017). Consistent with previous reports of increased levels of brain TNF $\alpha$ in animal models of AD (Jin et al., 2008), and consistent with the reports of
A

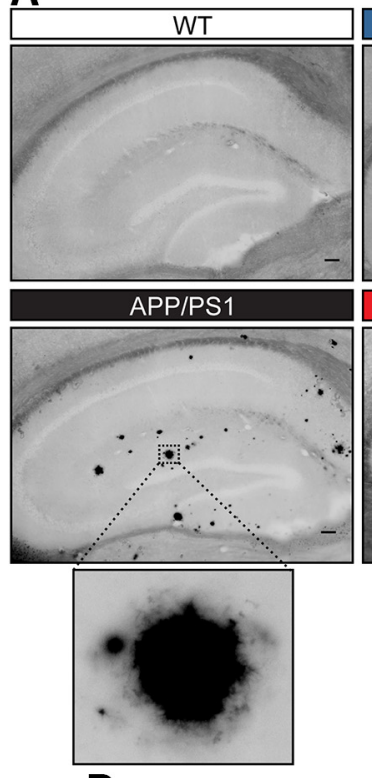

D

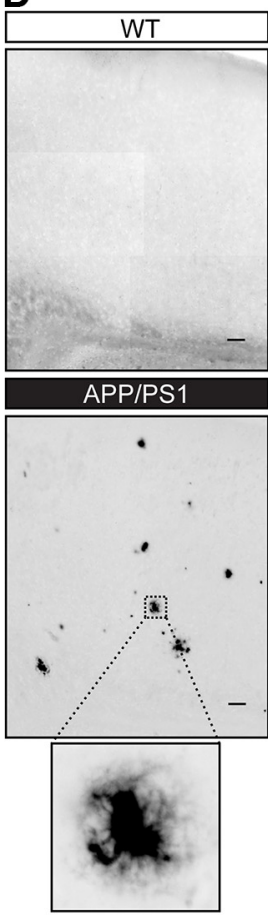

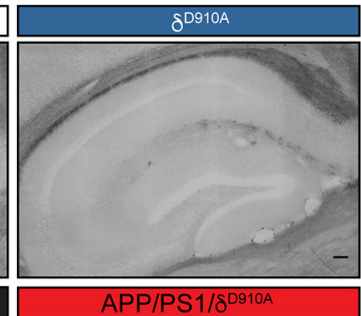
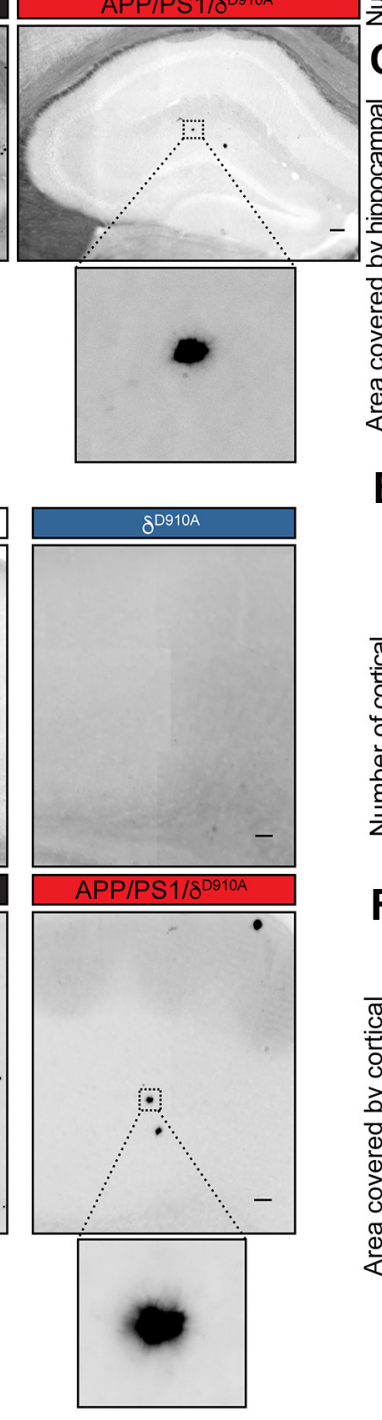

Figure 6. Amyloid plaque load is reduced in brain sections by genetic inactivation of PI3K $\delta$. $A$, Representative photomicrographs of hippocampal sections from mice of different genotypes stained for $A \beta$ plaques using Thioflavin $S . B, C$, Quantification of plaque number $(\boldsymbol{B})$ and size $(\boldsymbol{C})$ in the hippocampus of APP/PS1 and APP/PS1/ $\delta^{\text {D910A }}$ mice. $\boldsymbol{D}$, Representative photomicrograph of cortical sections stained with Thioflavin $S$. $\boldsymbol{E}, \boldsymbol{F}$, Quantification of plaque numbers $(\boldsymbol{E})$ and area covered by plaques $(\boldsymbol{F})$ in the cortex of experimental mice. Scale bar represents $100 \mu \mathrm{m}$. Data are displayed as mean \pm SEM, $n=4$ animals aged 6.5 -months-old per genotype and 3 replicates per animal (each replicate is a different section from the same brain region i. e. hippocampus or cortex), Student's $t$ test, ${ }^{*} p<0.05,{ }^{* *} p<0.01$. The statistical power of the results is specified in the Figure 6-1, available at https:// doi.org/10.1523/JNEUROSCI.0674-19.2019.f6-1. elevated levels of this cytokine in the blood (Fillit et al., 1991) and CSF (Tarkowski et al., 2003) of patients with AD, we found that the brain level of TNF $\alpha$ was increased in APP/PS1 mice. The role of microglia in neuroinflammation associated with AD is well established and several microglial receptors such as TREM2, CD33, and CR3, as well as their membrane adaptor TYROBP/ DAP12 (Pottier et al., 2016), are risk genes in the development of late-onset sporadic AD (Lambert et al., 2013). We previously 
A

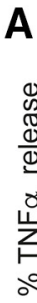

C
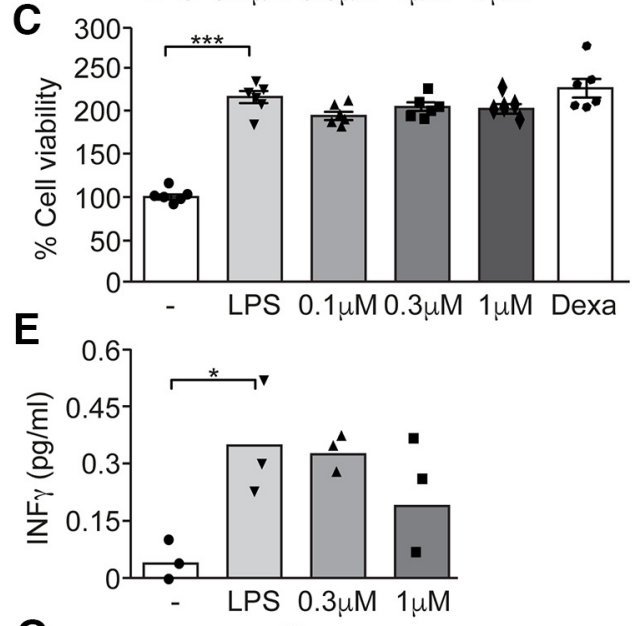

G

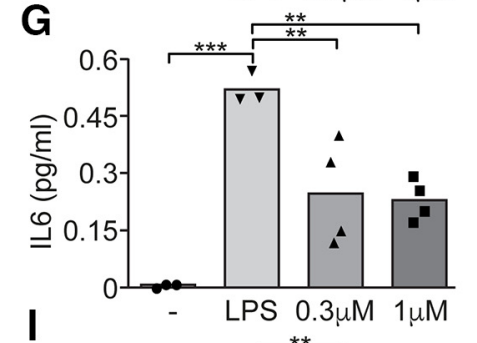

I

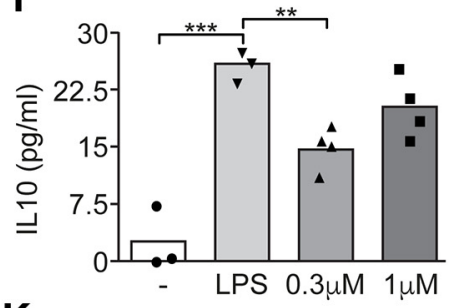

K

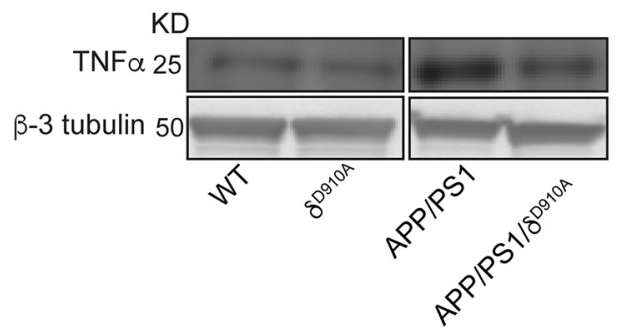

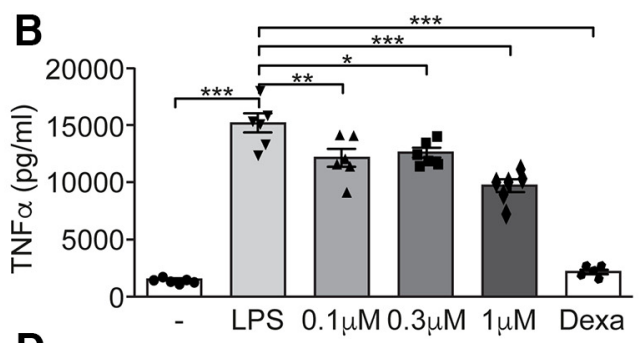

D
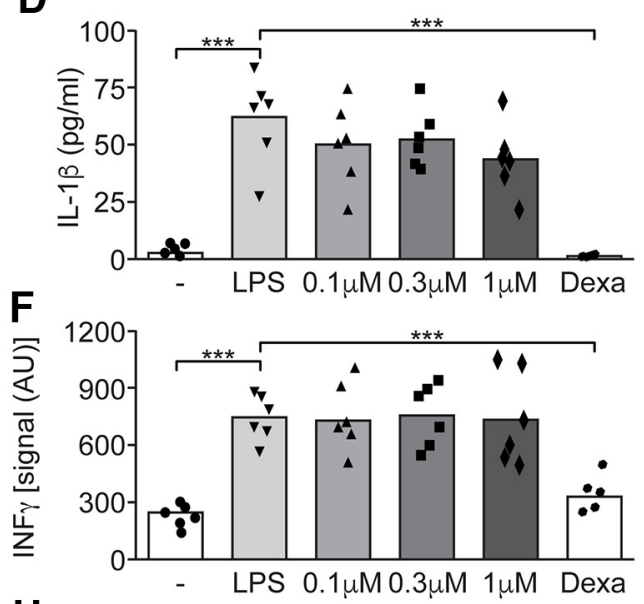

H
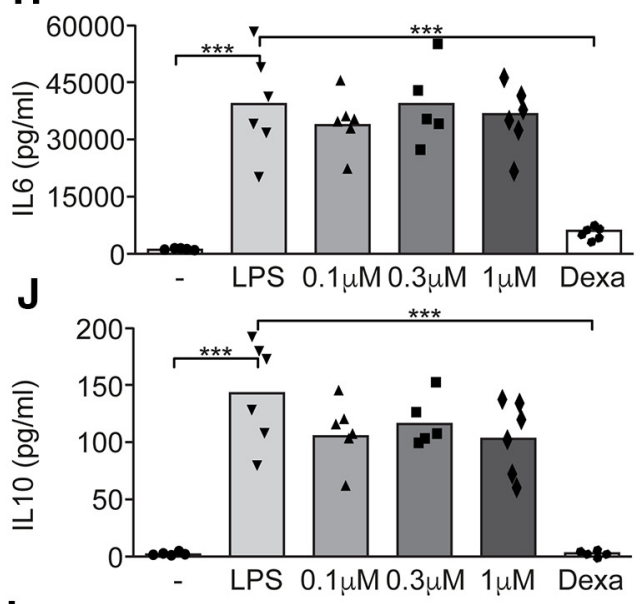

$\mathbf{L}$

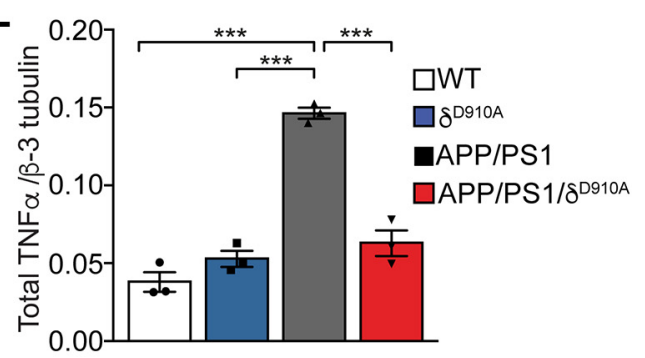

Figure 7. Genetic and pharmacological inactivation of PIJK $\delta$ activity ameliorate LPS-dependent release of TNF $\alpha$ in microglia and control TNF $\alpha$ levels in APP/PS1 mice. $A$, Relative TNF $\alpha$ release from Bv-2 murine-derived microglial cells, stimulated with LPS $(10 \mathrm{ng} / \mathrm{ml})$ for $8 \mathrm{~h}$ and treated with control vehicle (DMSO) or increasing concentrations of CAL-101 (0.1 $\mu \mathrm{m}, 0.3 \mu \mathrm{m}, 1$ or $3 \mu \mathrm{m})$. The data are expressed as percentage relative to LPS stimulation and DMSO treatment. $B$, TNF $\alpha$ release by mouse primary microglia stimulated for $24 \mathrm{~h}$ with control vehicle or LPS (100 $\mathrm{ng} / \mathrm{ml})$ and treated with DMSO or with increasing concentrations of "compound 12 " (0.1 $\mu \mathrm{M}, 0.3$ or $1 \mu \mathrm{M})$. C, MTT viability assay of mouse microglia after $24 \mathrm{~h}$ of control vehicle or LPS (100 ng/ml) stimulation and treatment with DMSO or increasing concentrations of "compound 12 " (0.1 $\mu \mathrm{M}, 0.3$ or $1 \mu \mathrm{M}) . \boldsymbol{D}, \boldsymbol{F}, \boldsymbol{H}, J$, Measurement of IL- $1 \beta, \mathrm{IFN} \gamma, \mathrm{IL}-6$, and IL-10 release, respectively, by mouse primary microglia stimulated for $12 \mathrm{~h}$ with control vehicle or LPS $(100 \mathrm{ng} / \mathrm{ml})$ and treated with DMSO or with increasing concentrations of "compound 12 " $(0.1 \mu \mathrm{M}, 0.3$ or $1 \mu \mathrm{M})$. The data are expressed as pg/ml or as intensity signal arbitrary units (AU) of the cytokine present in the collected supernatants. $E$, G, I, Measurement of IFN $\gamma$, IL-6, and IL-10 release, respectively, from of BV-2 murine-derived microglial cells, stimulated for $6 \mathrm{~h}$ with control vehicle or LPS $(10 \mathrm{ng} / \mathrm{ml})$ and treated with control (DMSO) or increasing concentrations of CAL-101 $(0.3$ or $1 \mu \mathrm{M})$. The data are expressed as pg/ml of the cytokine present in the collected supernatants. $\boldsymbol{K}$, Representative Western blot of TNF $\alpha$ from brains of 6.5 -month-old mice of different phenotypes. $\boldsymbol{L}$, Densitometric measurements of TNF $\alpha$ normalized to $\beta$-tubulin levels. Data are displayed as mean $\pm \mathrm{SEM}, n=3$ independent experiments with $n=4$ replicates in each experiment in $\boldsymbol{A}, n=5-6$ in $\boldsymbol{B}-\boldsymbol{J}, n=3$ animals per genotype in $\boldsymbol{J}$. One-way ANOVA followed by Bonferroni's post hoc test comparing all groups with the LPS group, ${ }^{*} p<0.05,{ }^{* *} p<0.01$ and ${ }^{* * *} p<0.001$ in $A-J$; one-way ANOVA followed by Bonferroni's post hoc test comparing all groups with the APP/PS1 group, ${ }^{* * *} p<0.001$ in $L$. 
A

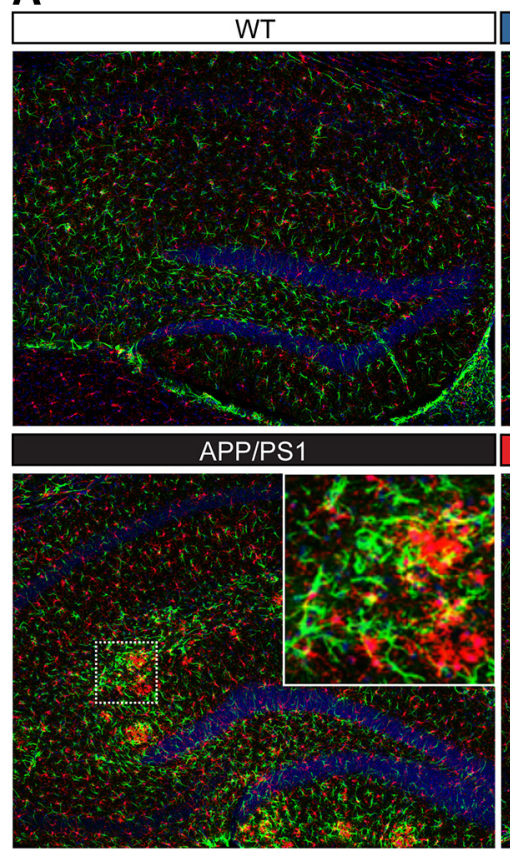

D

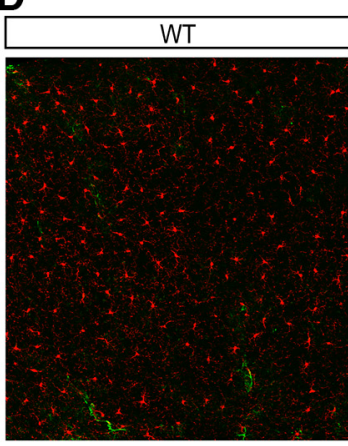

APP/PS1

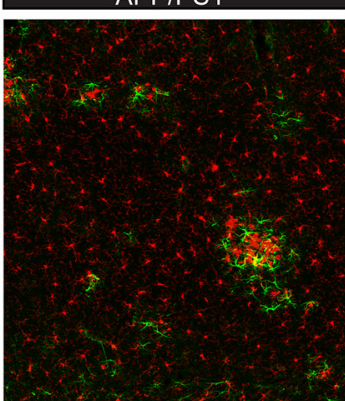

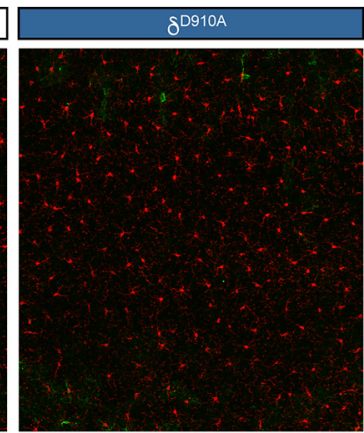
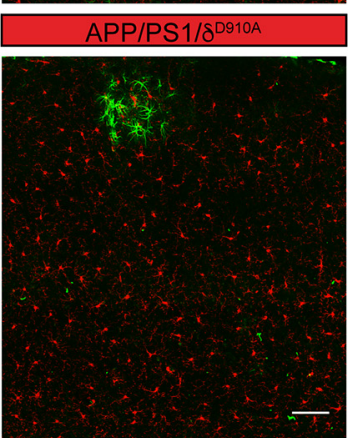

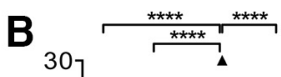

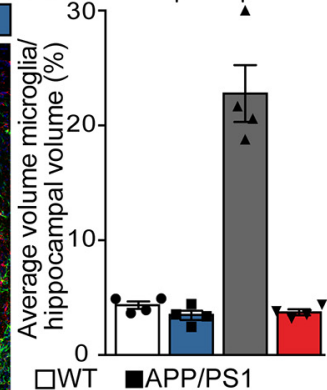

$\square W T$ aAPP/PS1

$\square \delta^{\mathrm{D} 910 \mathrm{~A}} \square \mathrm{APP} / \mathrm{PS} 1 / \delta^{\mathrm{D} 910 \mathrm{~A}}$

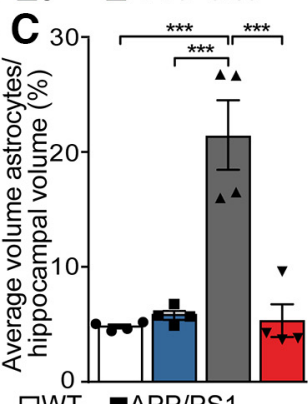

$\square W T$ 口APP/PS1

$\square$ S910A $^{\mathrm{DAPP}} / \mathrm{PS} 1 / \mathrm{\delta}^{\mathrm{D} 910 \mathrm{~A}}$
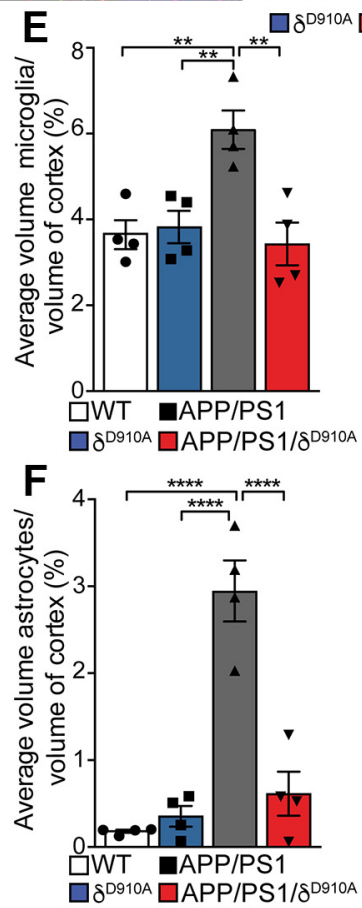

Figure 8. Brain gliosis in APP/PS1 mice is controlled by PI3K $\delta$ activity. $\boldsymbol{A}, \boldsymbol{D}$, Representative images of double fluorescence immunohistochemistry for microglia (Iba1, red), astrocytes (GFAP, green) and nuclei (DAPI, blue) in coronal hippocampal sections $(\boldsymbol{A})$ and coronal cortical sections $(\boldsymbol{D}) . \boldsymbol{B}, \boldsymbol{C}, \boldsymbol{E}, \boldsymbol{F}$, Tissue volume occupied by immunopositive structures calculated as a proportion of the total hippocampal volume imaged. Percentage volume of microglia $(\boldsymbol{B}, \boldsymbol{E})$ and astrocytes $(\boldsymbol{C}, \boldsymbol{F})$ in the hippocampus $(\boldsymbol{B}, \boldsymbol{C})$ and the cortex $(\boldsymbol{E}, \boldsymbol{F})$ of animals of different genotypes. Insets represent magnifications from each boxed area, showing regions of microglia and astrocyte accumulation. Scale bars, $100 \mu \mathrm{m}$ in $\boldsymbol{A}$ and $\boldsymbol{D}$. Data are displayed as mean \pm SEM of $n=4$ mice aged 6.5 months old per genotype and 3 replicates per animal (each replicate is a different section from the same brain structure -hippocampus or cortex-), one-way ANOVA followed by Bonferroni's post hoc test comparing all groups to the APP/PS1 group, ${ }^{* *} p<0.01,{ }^{* * *} p<0.001,{ }^{* * * *} p<0.0001$ in $B, C, E, F$. The statistical power of the results is specified in the Figure 8-1, available at https://doi.org/ 10.1523/JNEUROSCI.0674-19.2019.f8-1.

demonstrated that TNF $\alpha$ secretion after an inflammatory stimulus can be blocked by inhibiting PI $3 \mathrm{~K} \delta$, leading to the amelioration of the in vivo toxicity associated with ischemic stroke (Low et al., 2014). Here, we show that blockade of PI3K $\delta$ activity in primary microglia specifically affects the release of the proinflammatory cytokine TNF $\alpha$; none of the other proinflammatory or anti-inflammatory cytokines that we tested (IFN $\gamma$, IL-6, IL- $1 \beta$, and IL-10) was affected. Remarkably, we found that the elevation of TNF $\alpha$ levels observed in APP/PS1 mice was prevented in APP/ $\mathrm{PS} 1 / \delta^{\mathrm{D} 910 \mathrm{~A}}$ animals. Our results from Bv2 cells and primary cultured microglia suggest a direct effect of PI $3 \mathrm{~K} \delta$ inhibition on $\mathrm{TNF} \alpha$ trafficking and secretion. However, the reduced $\mathrm{A} \beta$ secretion and deposition observed in the APP/PS $1 / \delta^{\mathrm{D} 910 \mathrm{~A}}$ brains may also contribute to the reduction of TNF $\alpha$ levels (Jin et al., 2008). 

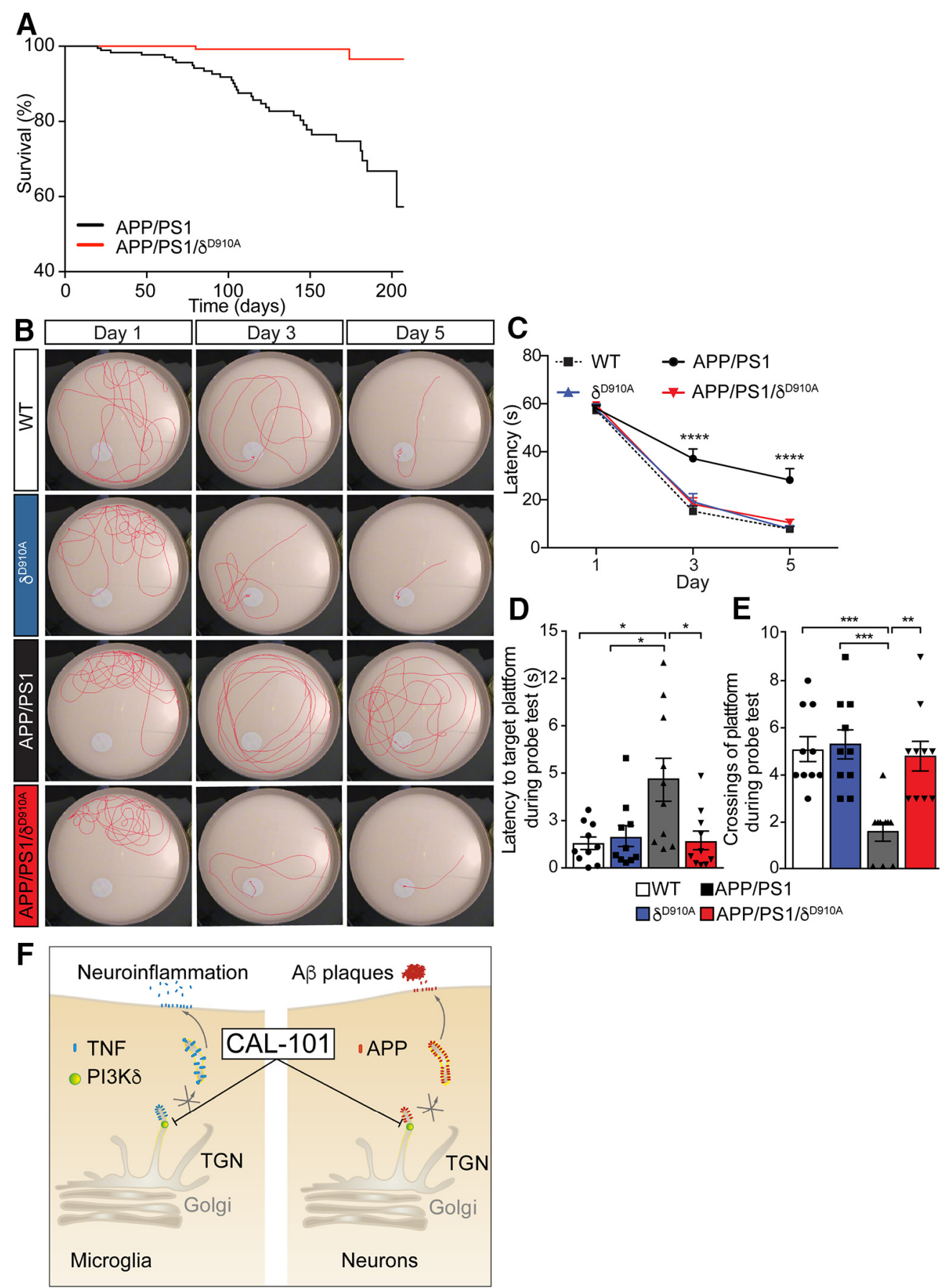

Figure 9. Genetic inactivation of PI3K $\delta$ increases survival and rescues spatial learning and memory of APP/PS1 mice. $A, A P P / P S 1$ transgenic mice $(n=131)$ present with a pronounced premature mortality that is ameliorated by inactivating PI3K $\delta(p<0.0001)$. Whereas the lethality was $42.7 \%$ in the APP/PS1 mice at the $210 \mathrm{~d}$ time point, in APP/PS1/ $\delta^{\mathrm{DP} 10 \mathrm{~A}}$ animals $(n=100)$ it was reduced to $3 \% . \boldsymbol{B}$, Representative images of swimming tracks for mice of different genotypes on days 1,3, and 5 of the learning phase of the Morris water maze. C, Learning acquisition plot measured as the time taken for mice to reach the submerged platform (latency) during the learning phase (daya 1,3, and day 5). $\boldsymbol{D}$, Latency to target the platform area during the probe test. $\boldsymbol{E}$, Number of platform crossings during the probe test. $\boldsymbol{F}$, Schematic diagram summarizing a model for the regulation of APP and TNF $\alpha$ trafficking by PI3K $\delta$ in neurons and microglia. PI3K $\delta$ is involved in the trafficking of APP and TNF $\alpha$ by controlling the formation of TGN-derived cargoes in neurons and microglia, respectively. By pharmacological modulation of PI3K $\delta$ activity using CAL-101, the release of neuronal $\mathrm{A} \beta$ and microglial TNF $\alpha$ can be attenuated, reducing the extent of A $\beta$ plaque formation and neuroinflammation. Data are displayed as mean \pm SEM of $n=10$ animals aged 6.5 months old per genotype, one-way ANOVA, ${ }^{*} p<0.05,{ }^{* *} p<0.01,{ }^{* * *} p<0.001,{ }^{* * * *} p<0.001$.

The genetic inactivation of PI3K $\delta$ activity might therefore have prevented the chronic $\mathrm{AD}$-associated chronic inflammatory response, as TNF $\alpha$ release from microglia is drastically reduced and the cytokine expression in the brain remains at basal levels, ensuring an effective clearance of newly formed $\mathrm{A} \beta$ in the brains of $\mathrm{APP} / \mathrm{PS} 1 / \delta^{\mathrm{D} 910 \mathrm{~A}}$ mice. Our results also clearly show that PI3K $\delta$ inhibition in a mouse model of AD strongly attenuates the accu- mulation of both astrocytes and microglia around plaques, suggesting attenuated proinflammatory feedback cascades and a decreased astrocytic toxic response, thereby reducing the neurotoxic microenvironment associated with amyloid plaques in the brain. Interestingly, genetic downregulation of TYROBP/DAP12 exerts a similar protective effect in the same mouse model (APP/ PS1) of AD (Haure-Mirande et al., 2017). It is, however, unlikely 
that TYROBP/DAP12 and PI3K $\delta$ act in the same pathway, as our results show that $\mathrm{PI} 3 \mathrm{~K} \delta$ acts on post-Golgi trafficking in both microglia (Low et al., 2014) and neurons whereas TYROBP/ DAP12 is expressed in microglia and dendritic cells (Audrain et al., 2018). The dual action of PI3K $\delta$ inhibition on neuronal APP processing and microglial TNF $\alpha$ secretion might ultimately be responsible for the combined beneficial effects observed in mice lacking this enzyme.

As reported previously (Serrano et al., 2010), the survival of APP/PS1 mice is reduced in comparison with that of WT animals. In addition to attenuating tissue pathology, genetic inhibition of $\mathrm{PI} 3 \mathrm{~K} \delta$ also increased the life expectancy of double mutant APP/ $\mathrm{PS} 1 / \delta^{\mathrm{D} 910 \mathrm{~A}}$ animals. Coincident with the accumulation of $\mathrm{A} \beta$ plaques within the brains of APP/PS1 mice, we and others have further demonstrated that these animals exhibit cognitive decline, as measured by the Morris water maze test at 6.5 months of age (Trinchese et al., 2004; Puzzo et al., 2014). Importantly, in $\mathrm{APP} / \mathrm{PS} 1 / \delta^{\mathrm{D} 910 \mathrm{~A}}$ mice, these memory deficits were fully rescued. There is a wealth of evidence to indicate that soluble $\mathrm{A} \beta$ oligomers can negatively affect synaptic transmission and plasticity (Klyubin et al., 2012). A $\beta$ plaques can also physically impede neurotransmission (Xu et al., 2015), making this the most likely explanation for the impaired cognitive performance of the APP/ $\mathrm{PS} 1$ animals. The reduced $\mathrm{A} \beta$ plaque load in the APP $/ \mathrm{PS} 1 / \delta^{\mathrm{D} 910 \mathrm{~A}}$ mice is therefore likely to underpin the rescue of the $A \beta$-induced cognitive decline in these animals. Significant neuroinflammation has also been correlated with both the onset and severity of cognitive impairment in $\mathrm{AD}$, being associated with neuronal dysfunction in animal models (Parachikova et al., 2007). TNF $\alpha$ is directly involved in the progression of this chronic inflammatory cascade (Bhaskar et al., 2014). Lowering TNF $\alpha$ and neuroinflammation reduces the progression of $\mathrm{AD}$, as reported previously by others (Cheng et al., 2014) and thus the inhibition of the TNF $\alpha$ driven chronic inflammatory cascade in APP/PS1/ $\delta^{\mathrm{D} 910 \mathrm{~A}}$ mice may contribute to the protection of these animals against cognitive impairment.

Selectively controlling chronic inflammation and $\mathrm{A} \beta$ plaques without affecting basal TNF $\alpha$ levels, as proposed here, offers significant advantages over current therapeutic strategies aimed at inhibiting TNF $\alpha$ action, the side-effects of which limit their potential. PI3K $\delta$ inhibitors have been approved for the treatment of B-cell malignancies and are undergoing trials in various inflammatory conditions (Bilanges et al., 2019). Our study therefore reinforces the importance of targeting both the neuronal and immunological components in the progression of $\mathrm{AD}$, and highlights the potential for pharmacologically targeting PI $3 \mathrm{~K} \delta$ in the clinic to simultaneously reduce $\mathrm{A} \beta$ generation and TNF $\alpha$ secretion. Such an approach is more specific and could be considered as a novel therapeutic for $\mathrm{AD}$, although it would require the development of PI $3 \mathrm{~K} \delta$ antagonists that can effectively cross the blood-brain barrier.

\section{References}

Ali K, Soond DR, Pineiro R, Hagemann T, Pearce W, Lim EL, Bouabe H, Scudamore CL, Hancox T, Maecker H, Friedman L, Turner M, Okkenhaug K, Vanhaesebroeck B (2014) Inactivation of PI(3)K p110delta breaks regulatory T-cell-mediated immune tolerance to cancer. Nature 510:407-411.

Andersen OM, Reiche J, Schmidt V, Gotthardt M, Spoelgen R, Behlke J, von Arnim CA, Breiderhoff T, Jansen P, Wu X, Bales KR, Cappai R, Masters CL, Gliemann J, Mufson EJ, Hyman BT, Paul SM, Nykjaer A, Willnow TE (2005) Neuronal sorting protein-related receptor sorLA/LR11 regulates processing of the amyloid precursor protein. Proc Natl Acad Sci U S A 102:13461-13466.
Audrain M, Haure-Mirande JV, Wang M, Kim SH, Fanutza T, Chakrabarty P, Fraser P, St George-Hyslop PH, Golde TE, Blitzer RD, Schadt EE, Zhang B, Ehrlich ME, Gandy S (2018) Integrative approach to sporadic Alzheimer's disease: deficiency of TYROBP in a tauopathy mouse model reduces $\mathrm{Clq}$ and normalizes clinical phenotype while increasing spread and state of phosphorylation of tau. Mol Psychiatry. In press.

Bates KA, Verdile G, Li QX, Ames D, Hudson P, Masters CL, Martins RN (2009) Clearance mechanisms of Alzheimer's amyloid-beta peptide: implications for therapeutic design and diagnostic tests. Mol Psychiatry 14:469-486.

Bero AW, Yan P, Roh JH, Cirrito JR, Stewart FR, Raichle ME, Lee JM, Holtzman DM (2011) Neuronal activity regulates the regional vulnerability to amyloid-beta deposition. Nat Neurosci 14:750-756.

Bhaskar K, Maphis N, Xu G, Varvel NH, Kokiko-Cochran ON, Weick JP, Staugaitis SM, Cardona A, Ransohoff RM, Herrup K, Lamb BT (2014) Microglial derived tumor necrosis factor-alpha drives Alzheimer's disease-related neuronal cell cycle events. Neurobiol Dis 62:273-285.

Bilanges B, Posor Y, Vanhaesebroeck B (2019) PI3K isoforms in cell signalling and vesicle trafficking. Nat Rev Mol Cell Biol. In press.

Bolmont T, Haiss F, Eicke D, Radde R, Mathis CA, Klunk WE, Kohsaka S, Jucker M, Calhoun ME (2008) Dynamics of the microglial/amyloid interaction indicate a role in plaque maintenance. J Neurosci 28:42834292.

Burgess BL, McIsaac SA, Naus KE, Chan JY, Tansley GH, Yang J, Miao F, Ross CJ, van Eck M, Hayden MR, van Nostrand W, St George-Hyslop P, Westaway D, Wellington CL (2006) Elevated plasma triglyceride levels precede amyloid deposition in Alzheimer's disease mouse models with abundant A beta in plasma. Neurobiol Dis 24:114-127.

Cheng X, Shen Y, Li R (2014) Targeting TNF: a therapeutic strategy for Alzheimer's disease. Drug Discov Today 19:1822-1827.

Collins JS, Perry RT, Watson B Jr, Harrell LE, Acton RT, Blacker D, Albert MS, Tanzi RE, Bassett SS, McInnis MG, Campbell RD, Go RC (2000) Association of a haplotype for tumor necrosis factor in siblings with lateonset alzheimer disease: the NIMH alzheimer disease genetics initiative. Am J Med Genet 96:823-830.

Colonna M, Butovsky O (2017) Microglia function in the central nervous system during health and neurodegeneration. Annu Rev Immunol 35: 441-468.

Dickson DW (1997) The pathogenesis of senile plaques. J Neuropathol Exp Neurol 56:321-339.

Edwards SR, Hamlin AS, Marks N, Coulson EJ, Smith MT (2014) Comparative studies using the Morris water maze to assess spatial memory deficits in two transgenic mouse models of Alzheimer's disease. Clin Exp Pharmacol Physiol 41:798-806.

Eickholt BJ, Ahmed AI, Davies M, Papakonstanti EA, Pearce W, Starkey ML, Bilancio A, Need AC, Smith AJ, Hall SM, Hamers FP, Giese KP, Bradbury EJ, Vanhaesebroeck B (2007) Control of axonal growth and regeneration of sensory neurons by the p110delta PI 3-kinase. PLoS One 2:e869.

El Khoury J, Toft M, Hickman SE, Means TK, Terada K, Geula C, Luster AD (2007) Ccr2 deficiency impairs microglial accumulation and accelerates progression of Alzheimer-like disease. Nat Med 13:432-438.

Ferrera D, Mazzaro N, Canale C, Gasparini L (2014) Resting microglia react to Abeta 42 fibrils but do not detect oligomers or oligomer-induced neuronal damage. Neurobiol Aging 35:2444-2457.

Fillit H, Ding WH, Buee L, Kalman J, Altstiel L, Lawlor B, Wolf-Klein G (1991) Elevated circulating tumor necrosis factor levels in Alzheimer's disease. Neurosci Lett 129:318-320.

Franklin KBJ, Paxinos G (2013) Paxinos and Franklin's The mouse brain in stereotaxic coordinates, Ed 4. Amsterdam: Academic.

Furman RR, Sharman JP, Coutre SE, Cheson BD, Pagel JM, Hillmen P, Barrientos JC, Zelenetz AD, Kipps TJ, Flinn I, Ghia P, Eradat H, Ervin T, Lamanna N, Coiffier B, Pettitt AR, Ma S, Stilgenbauer S, Cramer P, Aiello $\mathrm{M}$, et al (2014) Idelalisib and rituximab in relapsed chronic lymphocytic leukemia. N Engl J Med 370:997-1007.

Groemer TW, Thiel CS, Holt M, Riedel D, Hua Y, Huve J, Wilhelm BG, Klingauf J (2011) Amyloid precursor protein is trafficked and secreted via synaptic vesicles. PLoS One 6:e18754.

Haure-Mirande JV, Audrain M, Fanutza T, Kim SH, Klein WL, Glabe C, Readhead B, Dudley JT, Blitzer RD, Wang M, Zhang B, Schadt EE, Gandy S, Ehrlich ME (2017) Deficiency of TYROBP, an adapter protein for TREM2 and CR3 receptors, is neuroprotective in a mouse model of early Alzheimer's pathology. Acta Neuropathol 134:769-788. 
Hickman SE, Allison EK, El Khoury J (2008) Microglial dysfunction and defective beta-amyloid clearance pathways in aging Alzheimer's disease mice. J Neurosci 28:8354-8360.

Hoegenauer K, Soldermann N, Hebach C, Hollingworth GJ, Lewis I, von Matt A, Smith AB, Wolf RM, Wilcken R, Haasen D, Burkhart C, Zécri F (2016) Discovery of novel pyrrolidineoxy-substituted heteroaromatics as potent and selective PI3K delta inhibitors with improved physicochemical properties. Bioorg Med Chem Lett 26:5657-5662.

Hood VL, Berger R, Freedman R, Law AJ (2019) Transcription of PIK3CD in human brain and schizophrenia: Regulation by pro inflammatory cytokines. Hum Mol Genet. Advance online publication. Retrieved June 18, 2019. doi: $10.1093 / \mathrm{hmg} / \mathrm{ddz} 144$.

Horvath RJ, DeLeo JA (2009) Morphine enhances microglial migration through modulation of P2X4 receptor signaling. J Neurosci 29:998-1005.

Jankowsky JL, Slunt HH, Gonzales V, Jenkins NA, Copeland NG, Borchelt DR (2004) APP processing and amyloid deposition in mice haploinsufficient for presenilin 1. Neurobiol Aging 25:885-892.

Janus C (2004) Search strategies used by APP transgenic mice during navigation in the morris water maze. Learn Mem 11:337-346.

Jin JJ, Kim HD, Maxwell JA, Li L, Fukuchi K (2008) Toll-like receptor 4-dependent upregulation of cytokines in a transgenic mouse model of Alzheimer's disease. J Neuroinflammation 5:23.

Joensuu M, Martinez-Mármol R, Padmanabhan P, Glass NR, Durisic N, Pelekanos M, Mollazade M, Balistreri G, Amor R, Cooper-White JJ, Goodhill GJ, Meunier FA (2017) Visualizing endocytic recycling and trafficking in live neurons by subdiffractional tracking of internalized molecules. Nat Protoc 12:2590-2622.

Keller P, Toomre D, Díaz E, White J, Simons K (2001) Multicolour imaging of post-Golgi sorting and trafficking in live cells. Nat Cell Biol 3:140-149.

Klyubin I, Cullen WK, Hu NW, Rowan MJ (2012) Alzheimer's disease abeta assemblies mediating rapid disruption of synaptic plasticity and memory. Mol Brain 5:25.

Lambert JC, Ibrahim-Verbaas CA, Harold D, Naj AC, Sims R, Bellenguez C, DeStafano AL, Bis JC, Beecham GW, Grenier-Boley B, Russo G, ThortonWells TA, Jones N, Smith AV, Chouraki V, Thomas C, Ikram MA, Zelenika D, Vardarajan BN, Kamatani Y, et al. (2013) Meta-analysis of 74,046 individuals identifies 11 new susceptibility loci for Alzheimer's disease. Nat Genet 45:1452-1458.

Lampson BL, Brown JR (2017) PI3Kdelta-selective and PI3Kalpha/deltacombinatorial inhibitors in clinical development for B-cell non-Hodgkin lymphoma. Expert Opin Investig Drugs 26:1267-1279.

Lannutti BJ, Meadows SA, Herman SE, Kashishian A, Steiner B, Johnson AJ, Byrd JC, Tyner JW, Loriaux MM, Deininger M, Druker BJ, Puri KD, Ulrich RG, Giese NA (2011) CAL-101, a p110delta selective phosphatidylinositol-3-kinase inhibitor for the treatment of B-cell malignancies, inhibits PI3K signaling and cellular viability. Blood 117:591-594.

Liao YF, Wang BJ, Cheng HT, Kuo LH, Wolfe MS (2004) Tumor necrosis factor-alpha, interleukin-1beta, and interferon-gamma stimulate gammasecretase-mediated cleavage of amyloid precursor protein through a JNKdependent MAPK pathway. J Biol Chem 279:49523-49532.

Liddelow SA, Guttenplan KA, Clarke LE, Bennett FC, Bohlen CJ, Schirmer L, Bennett ML, Münch AE, Chung WS, Peterson TC, Wilton DK, Frouin A, Napier BA, Panicker N, Kumar M, Buckwalter MS, Rowitch DH, Dawson VL, Dawson TM, Stevens B, et al. (2017) Neurotoxic reactive astrocytes are induced by activated microglia. Nature 541:481-487.

Low PC, Misaki R, Schroder K, Stanley AC, Sweet MJ, Teasdale RD, Vanhaesebroeck B, Meunier FA, Taguchi T, Stow JL (2010) Phosphoinositide 3-kinase delta regulates membrane fission of Golgi carriers for selective cytokine secretion. J Cell Biol 190:1053-1065.

Low PC, Manzanero S, Mohannak N, Narayana VK, Nguyen TH, Kvaskoff D, Brennan FH, Ruitenberg MJ, Gelderblom M, Magnus T, Kim HA, Broughton BR, Sobey CG, Vanhaesebroeck B, Stow JL, Arumugam TV, Meunier FA (2014) PI3Kdelta inhibition reduces TNF secretion and neuroinflammation in a mouse cerebral stroke model. Nat Commun 5:3450.

Mandrekar-Colucci S, Landreth GE (2010) Microglia and inflammation in Alzheimer's disease. CNS Neurol Disord Drug Targets 9:156-167.

Minkeviciene R, Rheims S, Dobszay MB, Zilberter M, Hartikainen J, Fulop L, Penke B, Zilberter Y, Harkany T, Pitkänen A, Tanila H (2009) Amyloid beta-induced neuronal hyperexcitability triggers progressive epilepsy. J Neurosci 29:3453-3462.
Montgomery SL, Narrow WC, Mastrangelo MA, Olschowka JA, O’Banion MK, Bowers WJ (2013) Chronic neuron- and age-selective downregulation of TNF receptor expression in triple-transgenic Alzheimer disease mice leads to significant modulation of amyloid- and tau-related pathologies. Am J Pathol 182:2285-2297.

Muresan V, Ladescu Muresan Z (2015) Amyloid-beta precursor protein: multiple fragments, numerous transport routes and mechanisms. Exp Cell Res 334:45-53.

Nikolaev A, McLaughlin T, O'Leary DD, Tessier-Lavigne M (2009) APP binds DR6 to trigger axon pruning and neuron death via distinct caspases. Nature 457:981-989.

Okkenhaug K, Vanhaesebroeck B (2003) PI3K in lymphocyte development, differentiation and activation. Nat Rev Immunol 3:317-330.

Okkenhaug K, Bilancio A, Farjot G, Priddle H, Sancho S, Peskett E, Pearce W, Meek SE, Salpekar A, Waterfield MD, Smith AJ, Vanhaesebroeck B (2002) Impaired B and T cell antigen receptor signaling in p110delta PI 3-kinase mutant mice. Science 297:1031-1034.

Parachikova A, Agadjanyan MG, Cribbs DH, Blurton-Jones M, Perreau V, Rogers J, Beach TG, Cotman CW (2007) Inflammatory changes parallel the early stages of Alzheimer disease. Neurobiol Aging 28:1821-1833.

Pottier C, Ravenscroft TA, Brown PH, Finch NA, Baker M, Parsons M, Asmann YW, Ren Y, Christopher E, Levitch D, van Blitterswijk M, Cruchaga C, Campion D, Nicolas G, Richard AC, Guerreiro R, Bras JT, Zuchner S, Gonzalez MA, Bu G, Younkin S, et al. (2016) TYROBP genetic variants in early-onset Alzheimer's disease. Neurobiol Aging 48:222.e9-222.e15.

Puzzo D, Lee L, Palmeri A, Calabrese G, Arancio O (2014) Behavioral assays with mouse models of Alzheimer's disease: practical considerations and guidelines. Biochem Pharmacol 88:450-467.

Schindelin J, Arganda-Carreras I, Frise E, Kaynig V, Longair M, Pietzsch T, Preibisch S, Rueden C, Saalfeld S, Schmid B, Tinevez JY, White DJ, Hartenstein V, Eliceiri K, Tomancak P, Cardona A (2012) Fiji: an opensource platform for biological-image analysis. Nat Methods 9:676-682.

Schmidt V, Sporbert A, Rohe M, Reimer T, Rehm A, Andersen OM, Willnow TE (2007) SorLA/LR11 regulates processing of amyloid precursor protein via interaction with adaptors GGA and PACS-1. J Biol Chem 282:32956-32964.

Selkoe DJ (2002) Alzheimer's disease is a synaptic failure. Science 298:789_ 791.

Serrano J, Fernández AP, Martínez-Murillo R, Martínez A (2010) High sensitivity to carcinogens in the brain of a mouse model of Alzheimer's disease. Oncogene 29:2165-2171.

Stokin GB, Lillo C, Falzone TL, Brusch RG, Rockenstein E, Mount SL, Raman R, Davies P, Masliah E, Williams DS, Goldstein LS (2005) Axonopathy and transport deficits early in the pathogenesis of Alzheimer's disease. Science 307:1282-1288.

Tarkowski E, Andreasen N, Tarkowski A, Blennow K (2003) Intrathecal inflammation precedes development of Alzheimer's disease. J Neurol Neurosurg Psychiatry 74:1200-1205.

Tinevez JY, Perry N, Schindelin J, Hoopes GM, Reynolds GD, Laplantine E, Bednarek SY, Shorte SL, Eliceiri KW (2017) TrackMate: an open and extensible platform for single-particle tracking. Methods 115:80-90.

Trinchese F, Liu S, Battaglia F, Walter S, Mathews PM, Arancio O (2004) Progressive age-related development of alzheimer-like pathology in APP/ PS1 mice. Ann Neurol 55:801-814.

Viel JJ, McManus DQ, Smith SS, Brewer GJ (2001) Age- and concentrationdependent neuroprotection and toxicity by TNF in cortical neurons from beta-amyloid. J Neurosci Res 64:454-465.

Whitesell JD, Buckley AR, Knox JE, Kuan L, Graddis N, Pelos A, Mukora A, Wakeman W, Bohn P, Ho A, Hirokawa KE, Harris JA (2019) Whole brain imaging reveals distinct spatial patterns of amyloid beta deposition in three mouse models of Alzheimer's disease. J Comp Neurol 527:2122_ 2145.

Wyss-Coray T, Lin C, Yan F, Yu GQ, Rohde M, McConlogue L, Masliah E, Mucke L (2001) TGF-betal promotes microglial amyloid-beta clearance and reduces plaque burden in transgenic mice. Nat Med 7:612-618.

Xu K, Olsen O, Tzvetkova-Robev D, Tessier-Lavigne M, Nikolov DB (2015) The crystal structure of DR6 in complex with the amyloid precursor protein provides insight into death receptor activation. Genes Dev 29: 785-790. 